NBER WORKING PAPER SERIES

THE IMPACT OF NEW DRUG LAUNCHES ON LIFE-YEARS LOST IN 2015 FROM 19 TYPES OF CANCER IN 36 COUNTRIES

\author{
Frank R. Lichtenberg \\ Working Paper 24536 \\ http://www.nber.org/papers/w24536 \\ NATIONAL BUREAU OF ECONOMIC RESEARCH \\ 1050 Massachusetts Avenue \\ Cambridge, MA 02138 \\ April 2018
}

Financial support for this research was provided by Incyte Corporation and by the National Institute on Aging (Grant R24 AG048059). The views expressed herein are those of the author and do not necessarily reflect the views of the National Bureau of Economic Research.

NBER working papers are circulated for discussion and comment purposes. They have not been peer-reviewed or been subject to the review by the NBER Board of Directors that accompanies official NBER publications.

(C) 2018 by Frank R. Lichtenberg. All rights reserved. Short sections of text, not to exceed two paragraphs, may be quoted without explicit permission provided that full credit, including $($ ) notice, is given to the source. 
The Impact of New Drug Launches on Life-Years Lost in 2015 from 19 Types of Cancer in 36 Countries

Frank R. Lichtenberg

NBER Working Paper No. 24536

April 2018

JEL No. I10,J10,L65,O33

\begin{abstract}
This study employs a two-way fixed effects research design to measure the mortality impact and cost-effectiveness of cancer drugs: it analyzes the correlation across 36 countries between relative mortality from 19 types of cancer in 2015 and the relative number of drugs previously launched in that country to treat that type of cancer, controlling for relative incidence.

One additional drug for a cancer site launched during 2006-2010 is estimated to have reduced the number of 2015 disability-adjusted life years (DALYs) lost due to cancer at that site by 5.8\%. The estimated cost per life-year gained at all ages in 2015 from cancer drugs launched during 2006-2010 is \$1635.

We estimate that drugs launched during the entire 1982-2010 period reduced the number of cancer DALYs lost in 2015 by about 23\%. In the absence of new drug launches during 1982-2010, there would have been 26.3 million additional DALYs lost in 2015.
\end{abstract}

Frank R. Lichtenberg

Columbia University

504 Uris Hall

3022 Broadway

New York, NY 10027

and NBER

frl1@columbia.edu 


\section{The impact of new drug launches on life-years lost in 2015 from 19 types of cancer in 36 countries}

\section{Extended abstract}

This study employs a two-way fixed effects research design to measure the mortality impact and cost-effectiveness of cancer drugs: it analyzes the correlation across 36 countries between relative mortality from 19 types of cancer in 2015 and the relative number of drugs previously launched in that country to treat that type of cancer, controlling for relative incidence. The sample size (both in terms of number of observations and population covered) of this study is considerably larger than the sample sizes of previous studies; a new and improved method of analyzing the lag structure of the relationship between drug launches and life-years lost is used; and a larger set of measures of the burden of cancer is analyzed.

The number of disability-adjusted life-years (DALYs) and life-years lost are unrelated to drug launches 0-4 years earlier. This is not surprising, since utilization of a drug tends to be quite low during the first few post-launch years. Moreover, there is likely to be a lag of several years between utilization of a drug and its impact on mortality. However, mortality is significantly inversely related to the number of drug launches at least 5 years earlier, especially to drug launches 5-9 years earlier. One additional drug for a cancer site launched during 20062010 is estimated to have reduced the number of 2015 DALYs due to cancer at that site by 5.8\%; one additional drug launched during 1982-2005 is estimated to have reduced the number of 2015 DALYs by about 2.6\%. Lower quality (or effectiveness) of earlier-vintage drugs may account for their smaller estimated effect.

We estimate that drugs launched during the entire 1982-2010 period reduced the number of cancer DALYs in 2015 by about 23.0\%, and that, in the absence of new drug launches during 1982-2010, there would have been 26.3 million additional DALYs in 2015. Also, the 9 countries with the largest number of drug launches during 1982-2010 are estimated to have had 14\% fewer cancer DALYs (controlling for incidence) in 2015 than the 9 countries with the smallest number of drug launches during 1982-2010.

Estimates of the cost per life-year gained in 2015 from drugs launched during 2006-2010 range between \$1635 (life-years gained at all ages) and \$2820 (life-years gained before age 65). These estimates are similar to those obtained in previous country-specific studies of Belgium, Canada, and Mexico, and are well below the estimate obtained in one study of Switzerland. Mortality in 2015 is strongly inversely related to the number of drug launches in 20062010. If the relationship between mortality in 2020 and the number of drug launches in 20112015 is similar, drug launches 5-9 years earlier will reduce mortality even more (by 9.9\%) between 2015 and 2020 than they did (by 8.4\%) between 2010 and 2015. 


\section{Introduction}

During the period 1982-2014, 186 new chemical entities (NCEs) for treating cancer were launched worldwide: about 5.6 new cancer drugs per year. ${ }^{1}$ Moreover, the annual number of new cancer drug launches has been increasing: as shown in Figure 1, the number of new cancer drugs launched during 2005-2014 (76) was 77\% larger than the number launched during 19851994 (43). In contrast, the number of new drugs for other diseases (e.g. cardiovascular and infectious diseases) launched during 2005-2014 (242) was 42\% lower than the number launched during 1985-1994 (417). The acceleration in cancer drug innovation has contributed to sharply increasing cancer drug expenditure: costs of oncology therapeutics and supportive care drugs were $\$ 107$ billion globally in 2015, an increase of 11.5\% over 2014 (on a constant dollar basis) and up from $\$ 84$ billion in 2010, as measured at invoice price levels. These costs are expected to reach \$150 billion globally by 2020 (IMS Institute for Healthcare Informatics (2016, p. 4)).

The number of cancer drug launches has varied across cancer sites (breast, lung, colon, etc.). Figure 2 shows the average (across 36 countries) number of drug launches during 19822015 for 19 cancer sites. $^{2}$ The average number of launches was greater than 10 for 4 cancer sites (e.g. breast cancer and non-Hodgkin lymphoma), and lower than 2 for 4 cancer sites (e.g. thyroid cancer and Hodgkin lymphoma). The number of cancer drug launches has also varied across countries. Figure 3 shows the average (across the 19 cancer sites) number of drug launches during 1982-2015 for 36 countries. The mean number of cancer drugs launched in Canada (5.9) was $24 \%$ lower than the mean number of cancer drugs launched in the USA (7.8).

This study seeks to determine the extent to which the number of years of life lost (YLL) due to cancer ${ }^{3}$ in 36 countries in 2015 was reduced by previous launches of new cancer drugs,

\footnotetext{
${ }^{1}$ A New Molecular Entity (NME) or New Chemical Entity (NCE) is a drug or chemical that is without precedent among regulated and approved drug products. The NME designation indicates that a drug in development is not a version or derivative of an existing and previously investigated, trialed and approved substance. http://www.glossary.pharma-mkting.com/NME.htm

${ }^{2}$ Some cancer drugs are used to treat several types of cancer. I consider the launch of a drug used to treat 3 types of cancer as 3 launches: one launch for each type of cancer.

${ }^{3}$ If 100 people die from lung cancer at age 60, they have collectively lost $500(=100 *(65-60))$ years of life before age 65 , and $1500(=100 *(75-60)$ ) years of life before age 75 . Hence YLL depends on the number of deaths, age at death, and the age cutoff that is used. Brustugun et al (2014, p. 1014) argue that "number of years of life lost (YLL) may be a more appropriate indicator of [the] impact [of cancer] on society" than the number of deaths, and Burnet et al (2005, p. 241) argue that "years of life lost (YLL) from cancer is an important measure of population burden—and should be considered when allocating research funds.” Kirch (2008, p. 1365) also states that "the most widely used summary health indexes [which are used to analyze the benefits of health interventions] are: disability-
} 
and to measure the average cost-effectiveness of (cost per life-year gained from) those drugs. Several previous studies (Lichtenberg (2015, 2016a, 2016b, 2017)) have provided evidence about the mortality impact and cost-effectiveness of new cancer drugs in single (mostly small) countries (Canada, Belgium, Switzerland, and Mexico). These studies employed a difference-indifferences research design: they analyzed, within each country, the correlation across cancer sites between long-run increases in the number of drugs ever launched and mortality changes. All four studies found that new cancer drug launches had a significant negative impact on cancer mortality, and that new cancer drugs were highly cost-effective, according to a standard (based on per capita GDP) endorsed by the World Health Organization (WHO).

The present study will employ a two-way fixed effects research design (Somaini and Wolak (2016)): in effect, I will analyze the correlation across countries between relative mortality from each type of cancer in 2015 and the relative number of drugs previously launched in that country to treat that type of cancer, controlling for relative incidence. ${ }^{4}$ The mortality models I will estimate will include both country fixed effects, which control for the average (across cancer sites) level of cancer mortality in each country, and cancer-site fixed effects, which control for the average (across countries) level of mortality from each cancer site. This approach is feasible because the relative number of drugs launched for different types of cancer has varied considerably across countries. This is illustrated by Figure 4, which shows the number of drugs launched during 2006-2015 in Japan and Portugal for 19 types of cancer. ${ }^{5}$ The mean (across cancer sites) number of drugs launched during 2006-2015 was almost identical in Japan and Portugal (3.3 and 3.2, respectively), but Japan launched 4 more drugs for leukemia and 4 fewer drugs for ovary cancer. I will test the hypothesis that a relatively large number of drugs tend to be launched for a cancer site in a country when the relative incidence of cancer at that site in that country is high.

adjusted life years (DALY), quality-adjusted life years (QALY), healthy life expectancy (HALE), and years of potential life lost (YPLL).”

${ }^{4}$ A two-way fixed effects model in effect analyzes the correlation between $Y^{\prime}$ and $X$ ', where $Y^{\prime}=\left[\left(Y_{A 2}-Y_{A 1}\right)-\right.$ $\left.\left(Y_{\mathrm{B} 2}-\mathrm{Y}_{\mathrm{B} 1}\right)\right]$ and $\mathrm{Y}_{\mathrm{sc}}(\mathrm{s}=\mathrm{A}, \mathrm{B} ; \mathrm{c}=1,2)$ is the mean value of $\mathrm{Y}$ of observations where the first attribute equals $\mathrm{s}$ and the second attribute equals c; $\mathrm{X}$ ' and $\mathrm{X}_{\mathrm{sc}}$ are similarly defined. One of the most common types of two-way fixed effects models is a "difference-in-difference model," in which s refers to different sectors (e.g. industries or states), and c refers to different time periods. In the two-way fixed effects models that I will estimate, s will refer to 19 different cancer sites, and c will refer to 36 different countries. Although I will in effect be analyzing the correlation between Y' and X' (as defined above), to avoid confusion I won't refer to my model as a difference-in-differences model.

${ }^{5}$ Appendix Table 1 shows the number of drugs launched during 2006-2015, for all countries and cancer sites. 
In addition to providing a means of triangulating ${ }^{6}$ the results of earlier studies, the approach pursued in this study has a number of advantages. First, the sample size (both in terms of number of observations and population covered) of this study is considerably larger. Some of the previous studies were based on about 38 observations (19 cancer sites * 2 years (e.g. 2000 and 2011)); this study is based on 684 observations (19 cancer sites * 36 countries). The size of the population covered in this study (2322 million) is almost 13 times as large as the sum of the populations covered by the 4 previous studies (181 million). Second, a new and improved method of analyzing the lag structure of the relationship between drug launches and life-years lost will be used. ${ }^{7}$ Third, a larger set of measures of the burden of cancer will be analyzed: the number of disability-adjusted life-years (DALYs), the number of years of healthy life lost due to disability, and the number of life-years lost based on three different age thresholds.

In the next section, I provide background and motivation for the econometric model of life-years lost from cancer, which is developed in Section III. Data sources are discussed in Section IV. Section V provides evidence about the effect of incidence on the number of new drug launches. Cancer mortality model estimates are presented in Section VI. Implications of the results are discussed in Section VII. Section VIII concludes.

\section{Background and motivation}

Before describing the econometric model I will use to estimate the effect of new drug launches on life-years lost from cancer, I will provide some theoretical and empirical background and motivation for the model, which can be summarized by the following figure:

\begin{tabular}{|c|c|c|}
\hline $\begin{array}{l}\text { R\&D } \\
\text { - } \quad \text { Private } \\
\text { - } \quad \text { Public }\end{array}$ & $\begin{array}{l}\text { Technological progress (new ideas) } \\
\text { - } \quad \text { Embodied (new products) } \\
\text { - } \quad \text { Disembodied }\end{array}$ & $\begin{array}{l}\text { Economic growth } \\
\text { - } \quad \text { GDP growth } \\
\text { - } \quad \text { Longevity growth }\end{array}$ \\
\hline
\end{tabular}

Starting on the right of this figure: longevity increase is a very important part of economic growth, broadly defined. Nordhaus (2005) argued that "improvements in health status

\footnotetext{
${ }^{6}$ In the social sciences, triangulation is often used to indicate that two (or more) methods are used to check the results of one and the same subject. The idea is that one can be more confident with a result if different methods lead to the same result. https://en.wikipedia.org/wiki/Triangulation_(social_science)

${ }^{7}$ The new method allows us to test the hypothesis that, due to offsetting trends in drug quantity (utilization) and quality (effectiveness), the relationship between the year in which a drug was launched and its effect on mortality in 2015 is nonmonotonic (U-shaped).
} 
have been a major contributor to economic welfare over the twentieth century. To a first approximation, the economic value of increases in longevity in the last hundred years is about as large as the value of measured growth in non-health goods and services.” Murphy and Topel (2006) estimated that cumulative gains in life expectancy after 1900 were worth over $\$ 1.2$ million to the representative American in 2000, whereas post-1970 gains added about $\$ 3.2$ trillion per year to national wealth, equal to about half of GDP. The United Nations’ Human Development Index, which is used to rank countries into four tiers of human development, is a composite statistic of life expectancy, income per capita, and education (United Nations (2017)).

There is a consensus among macroeconomists that technological progress is the principal source of GDP growth. Romer (1990) argued that "growth...is driven by technological change that arises from intentional investment decisions made by profit-maximizing agents” (S71). Jones argued that "long-run growth is driven by the discovery of new ideas throughout the world." ${ }^{8}$ And Chien (2015) said that "it has been shown, both theoretically and empirically, that technological progress is the main driver of long-run growth.”

Since technological progress, or the discovery of new ideas, is the fundamental source of one of the major components_-GDP growth—of "human development," or economic growth, broadly defined, it is quite plausible that the discovery of new ideas has also played a major role in longevity growth. Some previous authors have suggested that this is the case. Fuchs (2010) said that "since World War II...biomedical innovations (new drugs, devices, and procedures) have been the primary source of increases in longevity," although he did not provide evidence to support this claim. Cutler, Deaton and Lleras-Muney (2006) performed a survey of a large and diverse literature on the determinants of mortality, and "tentatively identif[ied] the application of scientific advance and technical progress (some of which is induced by income and facilitated by education) as the ultimate determinant of health." They concluded that "knowledge, science, and technology are the keys to any coherent explanation” of mortality.

In general, measuring the number of ideas is challenging. One potential measure is the number of patents, but Patterson (2012, p. 8) noted that only 1\% of patent applications made by Bell Labs “generated [commercial] value.” Fortunately, measuring pharmaceutical “ideas” is

\footnotetext{
${ }^{8}$ The discovery of new ideas could increase economic output for two different reasons. First, output could simply be positively related to the quantity (and variety) of ideas ever discovered. Second, output could be positively related to the (mean or maximum) quality of ideas ever discovered, and new ideas may be better (of higher quality), on average, than old ideas.
} 
considerably easier than measuring ideas in general. The measure of pharmaceutical ideas I will use is the number of new molecular entities used to treat a disease launched in a country. Since we have precise information about when those ideas reached the market and the diseases to which they apply, we can assess the impact of those ideas on longevity in a two-way fixed effects framework.

Technological change may be either disembodied or embodied. Suppose firm X invests in $R \& D$, and that this investment results in a valuable discovery. If the technological advance is disembodied, consumers and other firms could benefit from the discovery without purchasing firm X's goods or services; they could benefit just by reading or hearing about the discovery. However, if the technological advance is embodied, consumers and other firms must purchase firm X's goods or services to benefit from its discovery. Solow (1960) argued that "many if not most innovations need to be embodied in new kinds of durable equipment before they can be made effective. Improvements in technology affect output only to the extent that they are carried into practice either by net capital formation or by the replacement of old-fashioned equipment by the latest models...”9 Romer (1990) also assumed that technological progress is embodied in new goods: "new knowledge is translated into goods with practical value," and "a firm incurs fixed design or research and development costs when it creates a new good. It recovers those costs by selling the new good for a price that is higher than its constant cost of production.” Hercowitz (1998, p. 223) concluded that “'embodiment’ is the main transmission mechanism of technological progress to economic growth.”

Most scholars agree with Jones’ (1998, pp. 89-90) statement that “technological progress is driven by research and development (R\&D) in the advanced world.” In 1997, the medical substances and devices sector was the most R\&D-intensive ${ }^{10}$ major industrial sector: almost twice as R\&D-intensive as the next-highest sector (information and electronics), and three times as R\&D-intensive as the average for all major sectors. (National Science Foundation (2017)). In 2007, 89\% of private biomedical research expenditure was funded by pharmaceutical and biotechnology firms; the remaining 11\% was funded by medical device firms (Dorsey et al (2010)).

\footnotetext{
${ }^{9}$ We hypothesize that innovations may be embodied in nondurable goods (e.g. drugs) and services as well as in durable equipment.

${ }^{10} \mathrm{R} \& \mathrm{D}$ intensity is the ratio of $\mathrm{R} \& \mathrm{D}$ to sales.
} 
A U.S. government institute (the National Cancer Institute (NCI)) has also played an important role in cancer drug discovery and development. ${ }^{11}$ Frequently, NCI’s drug development efforts focus on unmet needs that are not being adequately addressed by the private sector. NCI’s cancer drug discovery and development activities originated from a congressionally mandated initiative known as the Cancer Chemotherapy National Service Center (CCNSC), which, in 1955, established a national resource to facilitate the evaluation of potential anticancer agents. In 1976, the CCNSC's functions were incorporated into the Developmental Therapeutics Program (DTP) in NCI's Division of Cancer Treatment and Diagnosis (National Cancer Institute (2017)).

\section{Econometric model of life-years lost from cancer}

To investigate the impact that new drugs launched during 1982-2015 had on the number of years of life lost from cancer in 2015, conditional on incidence in 2012, I will estimate the following two-way fixed effects model:

$$
\begin{aligned}
\ln \left(\mathrm{Y}_{\mathrm{sc}}\right)=\beta_{0-4} & \text { LAUNCHES_2011_2015 } \mathrm{sc}+\beta_{5-9} \text { LAUNCHES_2006_2010 } \\
& +\beta_{10-14} \text { LAUNCHES_2001_2005 } \\
& +\gamma \ln (\text { CASES_2012 } \\
\mathrm{sc} & +\beta_{15-33}+\alpha_{\mathrm{s}}+\pi_{\mathrm{c}}+\varepsilon_{\mathrm{sc}}
\end{aligned}
$$

where $\mathrm{Y}_{\mathrm{sc}}$ is one of the following variables:

DALYS_2015 $s$ sc $=$ the number of disability-adjusted life years $\left(\right.$ DALYs) ${ }^{12}$ lost due to cancer at site s in country c in 2015

YLL_2015 1 sc $=$ the number of years of life lost (as measured in the WHO Global Burden of Disease Estimates) due to cancer at site s in country c in 2015

YLD_2015sc $=$ the number of years lost to disability due to cancer at site $\mathrm{s}$ in country c in 2015

\footnotetext{
${ }^{11}$ Sampat and Lichtenberg (2011) showed that government funding has played an indirect role—-for example, by funding basic underlying research that is built on in the drug discovery process-in almost half of the drugs approved and in almost two-thirds of priority-review drugs.

${ }^{12}$ The DALY is a summary measure which combines time lost through premature death and time lived in states of less than optimal health, loosely referred to as "disability". The DALY is a generalization of the well-known Potential Years of Life Lost measure (PYLLs) to include lost good health. One DALY can be thought of as one lost year of 'healthy' life and the measured disease burden is the gap between a population's health status and that of a normative reference population. DALYs for a specific cause are calculated as the sum of the YLLs from that cause and the YLDs for people living in states of less than good health resulting from the specific cause (World Health Organization (2017a), p. 5).
} 
YLL75_2015 sc $=$ the number of years of life lost before age 75 due to cancer at site $\mathrm{s}$ in country c in 2015

YLL65_2015sc $=$ the number of years of life lost before age 65 due to cancer at site s in country c in 2015

and

LAUNCHES_2011_2015 sc = the number of post-1981 ${ }^{13}$ new chemical entities used to treat cancer at site s launched in country c during 2011-2015

LAUNCHES_2006_2010 sc = the number of post-1981 new chemical entities used to treat cancer at site s launched in country c during 2006-2010

LAUNCHES_2001_2005sc = the number of post-1981 new chemical entities used to treat cancer at site s launched in country c during 2001-2005

LAUNCHES_1982_2000 $\mathrm{sc}$ = the number of post-1981 new chemical entities used to treat cancer at site s launched in country c during 1982-2000

CASES_2012 $2_{\mathrm{sc}}=$ the number of people diagnosed with cancer at site $\mathrm{s}$ in country c in 2012

$$
\begin{aligned}
& \alpha_{\mathrm{s}}=\text { a fixed effect for cancer at site s } \\
& \pi_{\mathrm{c}} \quad=\text { a fixed effect for country c }
\end{aligned}
$$

Eq. (1) will be estimated by weighted least squares, weighting by $\mathrm{Y}_{\mathrm{sc} .}{ }^{14}$ The disturbances of eq. (1) will be clustered within countries or within cancer sites.

In eq. (1), drugs launched in 4 different periods (0-4 years, 5-9 years, 10-14 years, and 15-33 years before 2015) are permitted to have different effects on mortality or disability in 2015. The model is specified in this way because the effect of a drug's launch on mortality is hypothesized to depend on both the quantity and the quality (or effectiveness) of the drug. Indeed, it is likely to depend on the interaction between quantity and quality: a quality improvement will have a greater impact on mortality if drug utilization (quantity) is high. Drugs

\footnotetext{
${ }^{13}$ My data on drug launches are left-censored: I only have data on drugs launched after 1981. A post-1981 new chemical entity is one that was first launched anywhere in the world after 1981.

${ }^{14}$ When eq. (1) is estimated without weighting, the residuals clearly exhibit heteroskedasticity: the variance of the residuals is strongly inversely related to $\mathrm{Y}_{\mathrm{sc}, 2015}$.
} 
launched in the 4 different periods are likely to vary (in opposite ways) with respect to both quantity (in 2015) and quality. Newer drugs are likely to be of higher quality than older drugs. ${ }^{15}$ On the other hand, utilization of new drugs tends to be much lower than utilization of old drugs.

To provide evidence about the process of diffusion of new medicines, I estimated the following model, using annual data for the period 2010-2014 on global utilization of 80 cancer drugs (molecules):

$$
\ln \left(N_{-} S U_{\mathrm{mn}}\right)=\rho_{\mathrm{m}}+\pi_{\mathrm{n}}+\varepsilon_{\mathrm{mn}}
$$

where

$$
\begin{aligned}
N_{\text {_SU }} \text { mn } & =\text { the number of standard units of molecule m sold worldwide } \mathrm{n} \\
& \text { years after it was first launched }(\mathrm{n}=0,1, \ldots, 17) \\
\rho_{\mathrm{m}} & =\text { a fixed effect for molecule } \mathrm{m} \\
\pi_{\mathrm{n}} & =\text { a fixed effect for age } \mathrm{n}
\end{aligned}
$$

Data on the world launch year of molecule m were obtained from the IMS Health New Product Focus database. Data on the annual number of standard units of molecule m sold worldwide during 2010-2014 were obtained from the IMS Health MIDAS database. The expression $\exp \left(\pi_{\mathrm{n}}\right.$ $-\pi_{5}$ ) is a "relative utilization index": it is the mean ratio of the quantity of a cancer drug sold $n$ years after it was launched to the quantity of the same drug sold 5 years after it was launched.

Estimates of the "relative utilization index" are shown in Figure5. These estimates indicate that utilization of a cancer drug is generally increasing, at a decreasing rate, with respect to time since launch. As shown in the following table, mean utilization of a drug is about twice as high 5-9 years after launch as it was 0-4 years after launch:

\begin{tabular}{|c|c|}
\hline years since launch & mean utilization (relative to utilization 5 years after launch) \\
\hline $0-4$ & 0.55 \\
\hline $5-9$ & 1.13 \\
\hline $10-14$ & 1.33 \\
\hline $15-31$ & 1.49 \\
\hline
\end{tabular}

\footnotetext{
${ }^{15}$ Grossman and Helpman (1993) argued that "innovative goods are better than older products simply because they provide more 'product services' in relation to their cost of production.” Bresnahan and Gordon (1996) stated simply that "new goods are at the heart of economic progress," and Bils (2004) said that "much of economic growth occurs through growth in quality as new models of consumer goods replace older, sometimes inferior, models.” As noted by Jovanovic and Yatsenko (2012), in "the Spence-Dixit-Stiglitz tradition...new goods [are] of higher quality than old goods."
} 
If the quality of later-vintage drugs is greater than the quality of earlier-vintage drugs, the relationship between the age of a drug (number of years since launch) and its impact on mortality (which depends on quality* quantity) may have an inverted-U shape. ${ }^{16}$ This is illustrated by Figure 6, which is based on the assumption that drug quality increases at a constant 3\% annual rate with respect to vintage (e.g. a drug launched in 2018 is 3\% better than a drug launched in 2017). Under this assumption, the drugs that have the largest impact on mortality are those that were launched 10 years before. Their impact would be $48 \%$ larger than that of drugs that were launched 30 years before, despite the fact that their utilization is 18\% lower, because their quality is $81 \%$ higher. $^{17}$

\section{Data and descriptive statistics}

Data on disability-adjusted life years (DALYs), years of life lost (YLL) and years lost due to disability (YLD) were obtained from the WHO Global Health Estimates 2015: Disease burden by Cause database (World Health Organization (2016a)). ${ }^{18}$ Data on years of potential life lost before ages 75 and 65 were constructed using data obtained from the WHO Global Health Estimates 2015: Deaths by Cause database (World Health Organization (2016b)).

That source provides data on the number of deaths by 5-year age group, cancer site, country, and year. I assume that all deaths in an age group occur at the midpoint of the age group, e.g. deaths in age-group 65-69 occur at age 67.5. Data on the number of patients diagnosed, by cancer site, country, and year, were obtained from GLOBOCAN 2002 (Ferlay et al (2004), a computer software package) and GLOBOCAN 2012 (International Agency for Research on Cancer (2017b)).

Summary statistics for the 19 major cancer sites in the 36 countries we analyze ${ }^{19}$ are shown in Table 1. In 2015, 76.6 million disability-adjusted life years were lost. Ninety-five

\footnotetext{
${ }^{16}$ The mortality impact will increase with respect to drug age (time since launch) if the rate of increase of quantity with respect to age is greater than the rate of decline of quality with respect to age; otherwise the mortality impact will decline.

${ }^{17}$ A smaller estimated impact on mortality of drugs launched in earlier periods could also be partly attributable to left-censoring of the data on drug launches: unmeasured launches of pre-1983 drugs were more likely to occur in earlier years than in more recent years.

${ }^{18}$ See World Health Organization (2017a) for a description of WHO methods and data sources for global burden of disease estimates.

${ }^{19}$ The 19 cancer sites account for 87\% of all cancer DALYs and about $80 \%$ of YLL65.
} 
percent of this loss was due to premature mortality, rather than to disability. The number of DALYs increased by 12\% between 2005 and 2015. However, the number of patients diagnosed 3 years earlier increased by 28\%. ${ }^{20}$ Therefore, the number of DALYs per patient diagnosed declined by $16 \%$ (= $28 \%-12 \%)$. The number of years of potential life lost before age 65 per patient diagnosed declined by even more: $25 \%$ (= 28\% - 3\%).

Data on drugs with indications for different types of cancer were obtained from the Thériaque database (Centre National Hospitalier d’Information sur le Médicament (2017)). . These data are shown in Appendix Table 2.

Data on drug launch years, by molecule and country, were obtained from the IMS Health New Product Focus database. These data are shown in Appendix Table 3. A blank cell indicates that the drug had not been launched in that country by the end of 2015.

Data on the annual number of standard units of cancer drugs sold worldwide during the period 2010-1014, by molecule, were obtained from the IMS Health MIDAS database.

\section{The effect of incidence on the number of new drug launches}

As discussed in the introduction, estimation of the two-way fixed effects model of lifeyears lost (eq. (1)) is feasible because the relative number of drugs launched for different types of cancer varies across countries, as illustrated by Figure 4. Why did Japan have more leukemia drug launches, but fewer ovary cancer drug launches, than Portugal? Previous studies have shown that both innovation (the number of drugs developed) and diffusion (the number of drugs launched in a country) depend on market size. Acemoglu and Linn (2004) found "economically significant and relatively robust effects of market size on innovation.” Danzon et al (2005) found that "countries with lower expected prices or smaller expected market size experience longer delays in new drug access, controlling for per capita income and other country and firm characteristics” (emphasis added).

The hypothesis that the number of drug launches is influenced by market size can be investigated in a two-way fixed effects framework by estimating the following equation:

$$
\text { N_LAUNCHES_2003_2012 } 2_{\mathrm{sc}}=\sigma \ln (\text { CASES_2002 } 2 \mathrm{sc})+\alpha_{\mathrm{s}}+\delta_{\mathrm{c}}+\varepsilon_{\mathrm{sc}}
$$

\footnotetext{
${ }^{20}$ Improved cancer screening and detection may account for part of this increase.
} 
where

N_LAUNCHES_2003_2012 $\mathrm{sc}=$ the number of drugs to treat cancer at site s launched in country c during 2003-2012

CASES_2002 $\mathrm{sc}=$ the number of patients diagnosed with cancer at site $\mathrm{s}$ in country c in 2002

The estimate of $\sigma$ is positive and significant: estimate $=0.1872$; standard error $=.0662 ; \mathrm{Z}=2.83$; $\mathrm{p}$-value $=.0047$. This signifies that larger relative market size (number of patients diagnosed) increases the relative number of drugs launched.

These findings are broadly consistent with the notion that "misery loves company” (Lichtenberg and Waldfogel (2009)): the relative number of drugs launched for a cancer site in a country is higher when the relative incidence of that cancer is greater. As illustrated by Figure 7, the direct positive effect of incidence on mortality may be partially offset by an indirect negative effect, via increased drug launches.

\section{Cancer mortality model estimates}

Estimates of parameters of eq. (1) are presented in Table 2; to conserve space, estimates of 19 cancer-site fixed-effects $\left(\alpha_{s}\right)$ and 36 country fixed effects $\left(\pi_{c}\right)$ are not shown. Rows 1-5 show estimates of eq. (1) when the dependent variable is $\ln \left(D A L Y S \_2015_{\text {sc }}\right.$ ). ${ }^{21}$ The estimate (in row 1) of $\beta_{0-4}$ is not statistically significant. This indicates that new drugs launched during 20112015 did not have a significant impact on the number of DALYs in 2015. This is not surprising since, as shown in Figure 5, utilization of a drug tends to be quite low during the first few years after it was launched. Moreover, there is likely to be a lag of several years between utilization of a drug and its impact on mortality. The estimate (in row 2) of $\beta_{5-9}$ is negative and highly significant (p-value < .0001). This indicates that new drugs launched during 2006-2010 had a highly significant negative impact on the number of DALYs in 2015. One additional drug for a cancer site launched during 2006-2010 is estimated to have reduced the number of 2015 DALYs due to cancer at that site by 5.8\%. The estimates (in rows 3 and 4 ) of $\beta_{10-14}$ and $\beta_{15+}$ are also negative and highly significant (p-value $\leq .0187$ ), but their magnitudes are about $45 \%$ of the

\footnotetext{
${ }^{21}$ Estimates of all parameters of this model are shown in Appendix Table 4.
} 
magnitude of $\beta_{5-9 .}{ }^{22}$ One additional drug for a cancer site launched during 1982-2005 is estimated to have reduced the number of 2015 DALYs due to cancer at that site by about 2.6\%. The smaller magnitudes of $\beta_{10-14}$ and $\beta_{15+}$ may be due to lower quality (or effectiveness) of earlier-vintage drugs, and to left-censoring of the drug launch data. Panel A of Figure 8 is a graph of the point estimates and 95\% confidence intervals of the estimates in rows 1-4. Row 5 of Table 2 shows the estimate of the coefficient $\gamma$ on the incidence variable, ln(CASES_2012 sc). As expected, this coefficient is positive and highly significant (p-value $<.0001$ ); the fact that it is significantly less than 1 may be partly attributable to errors in the measurement of incidence. ${ }^{23},{ }^{24}$

When we include the log of the number of cases in 2002 (In(CASES_2002 sc)) well as the $\log$ of the number of cases in 2012 in the model, the coefficient on $\ln$ (CASES_2002sc) is not statistically significant (estimate $=.064 ; \mathrm{Z}=1.35$; $\mathrm{p}$-value $=0.177$ ); the sum of the incidence coefficients is almost identical to the coefficient in row 5 of Table 2; and the estimates of the drug launch coefficients are virtually unchanged. Incidence is highly serially correlated: the estimate of $\kappa$ from the weighted (by CASES_2012sc) regression $\ln ($ CASES_2012sc) $=\kappa$ $\ln \left(\right.$ CASES_2002 $\left.2_{\mathrm{sc}}\right)+\alpha_{\mathrm{s}}+\pi_{\mathrm{c}}+\varepsilon_{\mathrm{sc}}$ is $0.778(\mathrm{Z}=15.58$; p-value $<.0001)$. When we include both $\ln ($ CASES_2002sc) and $\ln ($ CASES_2012sc $)$ in the model, and exclude both LAUNCHES_2001_2005sc and LAUNCHES_1982_2000sc, the estimate of $\beta_{0-4}$ is far from significant, and the estimate of $\beta_{5-9}$ remains highly significant ( $p$-value $=.0013$ ) and is slightly smaller than the estimate in row 2 of Table 2 (estimate $=-.051 ; Z=3.22$ ).

Rows 6-10 of Table 2 show estimates of eq. (1) when the dependent variable is $\ln ($ YLL_2015sc). The estimates of this equation are very similar to the estimates of the $\ln ($ DALYS_2015 sc) equation in rows 1-5. This is not surprising since, as noted above, 95\% of DALYs were due to premature mortality, rather than to disability. Rows 11-15 of Table 2 show estimates of eq. (1) when the dependent variable is ln(YLD_2015sc). The only drug launch coefficient that is statistically significant $(\mathrm{p}$-value $=.0254)$ is $\beta_{15+}$; it implies that one additional

\footnotetext{
22 The difference $\left(\beta_{5-9}-\beta_{10-14}\right)$ is highly significant ( $\mathrm{p}$-value $\left.=.0006\right)$; the difference $\left(\beta_{10-14}-\beta_{15+}\right)$ is insignificant ( $\mathrm{p}$ value $=.9149$ ).

${ }^{23}$ See http://globocan.iarc.fr/Pages/DataSource_and_methods.aspx for a discussion of GLOBOCAN 2012 incidence measurement.

${ }^{24}$ I also estimated eq. (1) where the dependent variable was the log of the number of deaths from cancer at site $\mathrm{s}$ in country $\mathrm{c}$ in 2015. The only launch coefficient that was statistically significant was the coefficient on LAUNCHES_2006_2010 (estimate $=-.031 ; \mathrm{Z}=2.49$; p-value $=.0127)$.
} 
drug for a cancer site launched during 1982-2000 reduced the number of years lost to disability due to cancer at that site in 2015 by $2.4 \%$.

Rows 16-20 and 21-25 of Table 2 show estimates of eq. (1) when the dependent variable is $\ln ($ YLL75_2015sc) and $\ln ($ YLL65_2015sc), respectively. The estimates are qualitatively similar to those in rows 1-5 and 6-10: the estimate of $\beta_{0-4}$ is insignificant; the estimates of the other launch coefficients are all negative and significant; and the magnitudes of $\beta_{10-14}$ and $\beta_{15+}$ are significantly smaller than the magnitude of $\beta_{5-9}$. But the magnitudes of $\beta_{5-9}, \beta_{10-14}$ and $\beta_{15+}$ are larger in rows 16-20 and 21-25 than they are in rows 1-5 and 6-10. For example, as shown in row 22, one additional drug for a cancer site launched during 2006-2010 is estimated to have reduced the number of years of potential life lost before age 65 due to cancer at that site in 2015 by $10.0 \%$. Panel B of Figure 8 is a graph of the point estimates and 95\% confidence intervals of the estimates in rows 21-24.

The estimates in Table 2 are based on data for 36 countries, including the United States. I estimated similar models using data for 35 countries, i.e. excluding the United States. These estimates are shown in Appendix Table 5. The magnitude of the point estimates based on the USA-excluded sample are generally about 15\% smaller than the magnitude of the point estimates based on the full sample (although some are larger), and the USA-excluded estimates are somewhat less significant. However, most of the estimates continue to be highly significant (pvalue $<.04)$, and the basic pattern of the estimates remains: DALYs and life-years lost are unrelated to drug launches 0-4 years earlier, and inversely related to drug launches at least 5 years earlier, especially to drug launches 5-9 years earlier.

\section{Discussion}

By combining the estimates in Table 2 with other data, we can estimate the number of life-years gained (i.e., the reduction in life-years lost) in 2015 attributable to previous new drug launches. We can also estimate expenditure in 2015 on these drugs, so we can obtain estimates

of an important indicator of cost-effectiveness: pharmaceutical expenditure per life-year gained.

Due to limitations of available data, we can estimate (under reasonable assumptions) expenditure in 2015 on drugs launched during 2006-2010, but we cannot estimate expenditure in 2015 on drugs launched during earlier periods. Therefore, although the estimates in Table 2 
indicate that drugs launched before 2006 as well as those launched during 2006-2010 reduced the number of life-years lost in 2015, I will only provide estimates of the cost-effectiveness in 2015 of drugs launched during 2006-2010. ${ }^{25}$

Calculations of the number of life-years gained in 2015 from, and of the costeffectiveness of, drugs launched during 2006-2010 are shown in Table 3. The first column shows the calculations for the first disease burden measure: disability-adjusted life-years. Row 1 shows the point estimates of the $\beta_{5-9}$ coefficients from Table 2 . Row 2 of Table 3 shows the weighted mean value of LAUNCHES_2006_2010, weighted by the corresponding disease burden measure. The average number of drugs launched during 2006-2010 for a cancer site was about 1.5. Row 3 shows the log-change in 2015 life-years lost due to LAUNCHES_2006_2010 $\left(=\beta_{5-9} *\right.$ mean(LAUNCHES_2006_2010)). The estimates imply that drugs launched during 2006-2010 reduced the number of cancer DALYs by about $8.4 \%(=-(\exp (-.087)-1))$. As shown in row 4, there were 88.1 million DALYs from all types of cancer in the 36 countries in 2015. The estimates imply that, in the absence of new drug launches during 2006-2010, there would have been 8.04 million additional DALYs. Similar calculations in columns 2-4 imply that, in the absence of new drug launches during 2006-2010, there would have been 8.28 million additional YLL (years of life lost at all ages), 4.51 million additional YLL75 (years of life lost before age 75), and 2.52 million additional YLL65 (years of life lost before age 65).

Additional calculations indicate that drugs launched during the entire 1982-2010 period reduced the number of cancer DALYs in 2015 by about 23.0\%, and that, in the absence of new drug launches during 1982-2010, there would have been 26.3 million additional DALYs in 2015. Also, the 9 countries with the largest number of drug launches during 1982-2010 (weighted by the coefficients in rows 2-4 of Table 2) are estimated to have had $14 \%$ fewer cancer DALYs (controlling for incidence) in 2015 than the 9 countries with the smallest number of drug launches during 1982-2010.

Calculations of 2015 expenditure on drugs launched during 2006-2010 are shown in rows 6-13. As shown in row 6, according to the IMS Institute for Healthcare Informatics (2016, p. 4), "the total [global] cost of oncology therapeutics and supportive care drugs rose from $\$ 90$ billion

\footnotetext{
${ }^{25}$ These drugs are probably more expensive than older drugs because they are more likely to retain patent protection; the estimates in Table 2 indicate that they are also more effective.
} 
in 2011 to $\$ 107$ billion in 2015, measured at invoice price levels.” ${ }^{26}$ The 36 countries in our sample accounted for 78\% of world pharmaceutical expenditure in 2014 (row 7); I assume that they also accounted for $78 \%$ of world oncology drug expenditure in 2015 , so I estimate the 36country cost of oncology therapeutics and supportive care drugs in 2015 to be $\$ 83.1$ billion (= $78 \% * \$ 107$ billion; row 8). This is an estimate of expenditure in the 36 countries in 2015 on all cancer drugs, i.e. drugs launched in all previous years. To estimate expenditure on cancer drugs launched during 2006-2010, we should multiply this estimate by the fraction of 2015 expenditure that was on drugs launched 5-9 years earlier. Data on expenditure in 2015, by molecule and country, are not available, but data on expenditure in 2010, by molecule and country, are available for 31 of the 36 countries from the IMS MIDAS database. As shown in row 9, those data indicate that about one-sixth (16\%) of 2010 pharmaceutical expenditure was on drugs launched in the respective country 5-9 years earlier (i.e. during 2001-2005). ${ }^{27}$ Assuming that the same fraction applies to 2015 cancer drug expenditure, 2015 expenditure in the 36 countries on cancer drugs launched during 2006-2010 was $\$ 13.5$ billion (=16\%* $\$ 83.1$ billion; row 10$)$. This is an estimate of expenditure by, or on behalf of, all cancer patients, i.e. patients of all ages. To calculate cost per-life year gained before ages 75 and 65, we require estimates of the fractions of cancer drug expenditure by, or on behalf of, cancer patients below ages 75 and 65 . According to GLOBOCAN 2012, globally 76\% of cancer patients are diagnosed before age 75 , and 52\% are diagnosed before age 65 (International Agency for Research on Cancer (2017b); row 11). I therefore assume that $76 \%$ of cancer drug expenditure was on patients below age 75 , and $52 \%$ of cancer drug expenditure was on patients below age 65 (row 12). These estimates may be conservative (i.e. overestimates), because some drug expenditure on a patient diagnosed before age $\mathrm{x}$ may occur after the patient is older than age $\mathrm{x}$.

Estimates of the cost-effectiveness measure - the ratio of estimated 2015 expenditure on drugs launched during 2006-2010 (row 12) to the reduction in 2015 life-years lost due to those drugs (row 5) - are shown in row 13. The estimated cost per life-year gained ranges between

\footnotetext{
${ }^{26}$ This amount is $9.74 \%$ of world pharmaceutical expenditure (\$1098 million) in 2014 (International Federation of Pharmaceutical Manufacturers \& Associations (2017, Annex 2)). According to the IMS Institute, “the U.S. derives $11.5 \%$ of its total drug costs from oncology, up from $10.5 \%$ in 2011 . In developed countries, between $8.6 \%$ and $15.9 \%$ of the total drug bill is spent on oncology and supportive care medicines. Oncology accounts for a smaller portion of total medicines costs in pharmerging countries, where between $2.5 \%$ and $11.5 \%$ of total drug cost is for cancer treatments” (IMS Institute for Healthcare Informatics (2016, p. 22).

27 That estimate applies to all drugs, not just cancer drugs.
} 
\$1635 (life-years gained at all ages) and \$2820 (life-years gained before age 65. These estimates are similar to those obtained in three previous country-specific studies (Belgium: $€ 1311$ (Lichtenberg (2016a)); Mexico \$2146 (Lichtenberg (2017)); Canada: \$2730 (Lichtenberg (2015))); it is well below the estimate obtained in one country-specific study (Switzerland: \$21,228-\$28,673 (Lichtenberg (2016b))).

As noted by Bertram et al (2016), authors writing on behalf of the WHO’s Choosing Interventions that are Cost-Effective project (WHO-CHOICE) suggested in 2005 that “interventions that avert one DALY for less than average per capita income for a given country or region are considered very cost-effective; interventions that cost less than three times average per capita income per DALY averted are still considered cost-effective.” Population-weighted average per capita income (GDP) in the 36 countries in 2015 was \$US 21,359, so these estimates indicate that the new drugs launched during 2006-2010 were very cost-effective, overall.

Two considerations suggest that the figures in row 13 of Table 3 may overestimate the true net cost per life-year gained. First, those estimates are based on drug cost measured at invoice price levels, but "cancer medicines are subject to different types of off-invoice discounts, rebates and price concessions based on how the medicines are reimbursed or administered to patients” (IMS Institute for Healthcare Informatics (2016, p. 26)). ${ }^{28}$ Second, a previous study based on U.S. data (Lichtenberg (2014)) showed that about 25\% of the cost of new drugs (for all diseases) is offset by reduced expenditure on old drugs. ${ }^{29}$

\section{Summary}

Several previous studies have provided evidence about the mortality impact and costeffectiveness of new cancer drugs in single (mostly small) countries, by employing one kind of two-way fixed effects research design: they analyzed, within each country, the correlation across cancer sites between long-run increases in the number of drugs ever launched and mortality changes. This study has employed a different kind of two-way fixed effects research design to

\footnotetext{
${ }^{28}$ According to the IMS Institute, in the U.S., net price growth on existing branded oncology drugs is estimated to have averaged $4.8 \%$ in 2015, versus 6.4\% invoice price growth. In Europe, a range of discounts and other mechanisms also exist, resulting in lower realized prices by manufacturers" (IMS Institute for Healthcare Informatics (2016, p. 5).

${ }^{29}$ That study also demonstrated that pharmaceutical innovation has reduced work-loss days.
} 
measure the mortality impact and cost-effectiveness of cancer drugs: it analyzed the correlation across 36 countries between relative mortality from 19 types of cancer in 2015 and the relative number of drugs previously launched in that country to treat that type of cancer, controlling for relative incidence. The sample size (both in terms of number of observations and population covered) of this study was considerably larger than the sample sizes of previous studies; a new and improved method of analyzing the lag structure of the relationship between drug launches and life-years lost was used; and a larger set of measures of the burden of cancer was analyzed. We showed that the relative number of drugs launched for a cancer site in a country is positively related to relative market size (number of patients diagnosed).

DALYs and life-years lost are unrelated to drug launches 0-4 years earlier. This is not surprising, since utilization of a drug tends to be quite low during the first few post-launch years. Moreover, there is likely to be a lag of several years between utilization of a drug and its impact on mortality. However, mortality is significantly inversely related to the number of drug launches at least 5 years earlier, especially to drug launches 5-9 years earlier. One additional drug for a cancer site launched during 2006-2010 is estimated to have reduced the number of 2015 DALYs due to cancer at that site by 5.8\%; one additional drug launched during 1982-2005 is estimated to have reduced the number of 2015 DALYs by about 2.6\%. Lower quality (or effectiveness) of earlier-vintage drugs may account for their smaller estimated effect.

When the United States is excluded from the sample, the magnitude of the point estimates is generally about $15 \%$ smaller than the magnitude of the point estimates based on the full sample (although some are larger), and the USA-excluded estimates are somewhat less significant. However, most of the estimates continue to be highly significant (p-value $<.04$ ), and the basic pattern of the estimates remains.

The estimates implied that drugs launched during 2006-2010 reduced the number of cancer DALYs in 2015 by about 8.7\% and that, in the absence of new drug launches during 2006-2010, there would have been 8.04 million additional DALYs due to cancer in the 36 countries. The estimates also implied that, in the absence of new drug launches during 20062010, there would have been 4.51 million additional years of life lost before age 75, and 2.52 million additional years of life lost before age 65 .

We also estimated that drugs launched during the entire 1982-2010 period reduced the number of cancer DALYs in 2015 by about 23.0\%, and that, in the absence of new drug launches 
during 1982-2010, there would have been 26.3 million additional DALYs in 2015. Also, the 9 countries with the largest number of drug launches during 1982-2010 are estimated to have had 14\% fewer cancer DALYs (controlling for incidence) in 2015 than the 9 countries with the smallest number of drug launches during 1982-2010.

Estimates of the cost per life-year gained in 2015 from drugs launched during 2006-2010 ranged between \$1635 (life-years gained at all ages) and \$2820 (life-years gained before age 65). These estimates are similar to those obtained in previous country-specific studies of Belgium, Canada, and Mexico, and are well below the estimate obtained in one study of Switzerland. Mortality in 2015 is strongly inversely related to the number of drug launches in 20062010. If the relationship between mortality in 2020 and the number of drug launches in 20112015 is similar, drug launches 5-9 years earlier will reduce mortality even more (by 9.9\%) between 2015 and 2020 than they did (by 8.4\%) between 2010 and 2015.

\section{Acknowledgement}

Financial support for this research was provided by Incyte Corporation and by the National Institute on Aging (Grant R24 AG048059).

\section{References}

Acemoglu, Daron and Joshua Linn (2004) Market size in innovation: theory and evidence from the pharmaceutical industry. Quarterly Journal of Economics 119 (3), 1049-1090, August.

Bertram, Melanie Y, Jeremy A Lauer, Kees De Joncheere, Tessa Edejer, Raymond Hutubessy, Marie-Paule Kieny and Suzanne R Hill (2016) Cost-effectiveness thresholds: pros and cons. Bulletin of the World Health Organization 94(12), 925-930, Dec 1.

Bils, Mark (2004) Measuring the Growth from Better and Better Goods. National Bureau of Economic Research working paper no. 10606, July.

Bresnahan, Timothy F and Robert J Gordon (1996) The Economics of New Goods (Chicago: University of Chicago Press).

Brustugun, OT, B Møller, and A Helland (2014) Years of life lost as a measure of cancer burden on a national level. British Journal of Cancer 111, 1014-1020. 
Burnet, NG, SJ Jefferies, RJ Benson, DP Hunt, and FP Treasure (2005) Years of life lost (YLL) from cancer is an important measure of population burden--and should be considered when allocating research funds. British Journal of Cancer 92 (2), 241-5, January.

Centre National Hospitalier d’Information sur le Médicament (2017) Thériaque database. http://www.theriaque.org/apps/contenu/accueil.php

Chien, YiLi (2015) What Drives Long-Run Economic Growth?. Federal Reserve Bank of St. Louis.

Cutler, David, Angus Deaton, and Adriana Lleras-Muney (2006) The Determinants of Mortality. Journal of Economic Perspectives 20(3), 97-120, Summer.

Danzon, Patricia M, Y Richard Wang, and Liang Wang (2005) The impact of price regulation on the launch delay of new drugs-evidence from twenty-five major markets in the 1990s. Health Economics 14(3), 269-92, March.

Dorsey, E Ray, Jason de Roulet, Joel P. Thompson, Jason I. Reminick, Ashley Thai, Zachary White-Stellato, Christopher A. Beck, Benjamin P. George, and Hamilton Moses III (2010) Financial Anatomy of Biomedical Research, 2003 - 2008. Journal of the American Medical Association 303(2), 137-143, January 13.

Ferlay J, F Bray, P Pisani, and D M Parkin (2004) GLOBOCAN 2002 Cancer Incidence, Mortality and Prevalence Worldwide, IARC CancerBase No. 5, version 2.0, IARCPress, Lyon.

Fuchs, Victor R (2010) New Priorities for Future Biomedical Innovations. New England Journal of Medicine 363,704-706, August 19,

Grossman, Gene M., and Elhanan Helpman (1993) Innovation and Growth in the Global Economy (Cambridge: MIT Press).

Hercowitz, Zvi (1998) The 'embodiment' controversy: A review essay. Journal of Monetary Economics 41, 217-224.

IMS Institute for Healthcare Informatics (2015) Medicines Use and Spending Shifts: A Review of the Use of Medicines in the U.S. in 2014, April.

IMS Institute for Healthcare Informatics (2016) Global Oncology Trend Report: A Review of 2015 and Outlook to 2020, June.

International Agency for Research on Cancer (2017a) WHO Cancer Mortality Database.

International Agency for Research on Cancer (2017b) GLOBOCAN 2012: Estimated Cancer Incidence, Mortality, and Prevalence Worldwide in 2012. 
International Federation of Pharmaceutical Manufacturers \& Associations (2017) The Pharmaceutical Industry and Global Health: Facts and Figures 2017. February, https://www.ifpma.org/wp-content/uploads/2017/02/IFPMA-Facts-And-Figures-2017.pdf

Jones, Charles I (1998) Introduction to Economic Growth. New York: W.W. Norton.

Jones Charles I (2002) Sources of U.S. Economic Growth in a World of Ideas. American Economic Review 92 (1): 220-239, March.

Jovanovic Boyan, and Yuri Yatsenko (2012) Investment in Vintage Capital. Journal of Economic Theory 147(2), 551-569.

Kirch, Wilhelm, ed. (2008) Encyclopedia of Public Health, Springer-Verlag Berlin Heidelberg.

Lichtenberg Frank R (2014) The impact of pharmaceutical innovation on disability days and the use of medical services in the United States, 1997-2010. Journal of Human Capital 8(4), 432480, Winter.

Lichtenberg Frank R (2015) The Impact of Pharmaceutical Innovation on Premature Cancer Mortality in Canada, 2000-2011. International Journal of Health Economics and Management 15(3), 339-359, June.

Lichtenberg Frank R (2016a) The impact of pharmaceutical innovation on cancer mortality in Belgium, 2004-2012. Forum for Health Economics and Policy 20:1.

Lichtenberg Frank R (2016b) The impact of pharmaceutical innovation on premature cancer mortality in Switzerland, 1995-2012. European Journal of Health Economics 17 (7), 833-854, September.

Lichtenberg Frank R (2017) The impact of pharmaceutical innovation on cancer mortality in Mexico, 2003-2013. Latin American Economic Review 26:8, December.

Lichtenberg Frank R, Waldfogel Joel (2009) Does Misery Love Company? Evidence from Pharmaceutical Markets Before and After the Orphan Drug Act. Michigan Telecommunications \& Technology Law Review 335.

Murphy Kevin M, and Robert H Topel (2006) The Value of Health and Longevity. Journal of Political Economy 114 (5).

National Cancer Institute (2017) Enhancing Drug Discovery and Development.

National Science Foundation (2017) R\&D Expenditures by Industry Category.

Nordhaus, William D (2005) Irving Fisher and The Contribution of Improved Longevity to Living Standards. American Journal of Economics and Sociology 64(1): 367-392, January. 
OECD (2017) OECD Health Statistics database.

Patterson, Gregory S (2012) The Business of Ideas: The Highs and Lows of Inventing and Extracting Revenue from Intellectual Property, AuthorHouse, September 14.

Romer, Paul M (1990) Endogenous Technological Change. Journal of Political Economy 98(5, Pt. 2), S71-S102, October.

Sampat, Bhaven, Frank R Lichtenberg (2011) What are the Respective Roles of the Public and Private Sectors in Pharmaceutical Innovation?. Health Affairs 30(2), 332-9, Feb.

Solow, Robert (1960) Investment and Technological Progress. In Mathematical methods in the social sciences, 1959, edited by Kenneth Arrow, Samuel Karlin, and Patrick Suppes. Stanford, CA: Stanford University Press.

Somaini, Paulo, and Frank A Wolak (2016) An Algorithm to Estimate the Two-Way Fixed Effects Model. Journal of Econometric Methods 5(1): 143-152, January.

United Nations (2017) Human Development Index (HDI) | Human Development Reports.

World Health Organization (2016a) Global Health Estimates 2015: Disease burden by Cause, Age, Sex, by Country and by Region, 2000-2015. Geneva, World Health Organization; 2016.

World Health Organization (2016b) Global Health Estimates 2015: Deaths by Cause, Age, Sex, by Country and by Region, 2000-2015. Geneva, World Health Organization; 2016.

http://www.who.int/healthinfo/global_burden_disease/estimates/en/index1.html

World Health Organization (2017a) WHO methods and data sources for global burden of disease estimates 2000-2015, Global Health Estimates Technical Paper WHO/HIS/IER/GHE/2017.1, January, http://www.who.int/healthinfo/global_burden_disease/GlobalDALYmethods_2000_2015.pdf

World Health Organization (2017b) WHO methods and data sources for country-level causes of death 2000-2015, Global Health Estimates Technical Paper WHO/HIS/IER/GHE/2016.3, Department of Information, Evidence and Research, http://www.who.int/healthinfo/global_burden_disease/GlobalCOD_method_2000_2015.pdf 
Figure 1

Number of new cancer drugs and other new drugs launched worldwide, 1985-1994 and 2005-2014

450

400

350

300

250

200

150

100

50

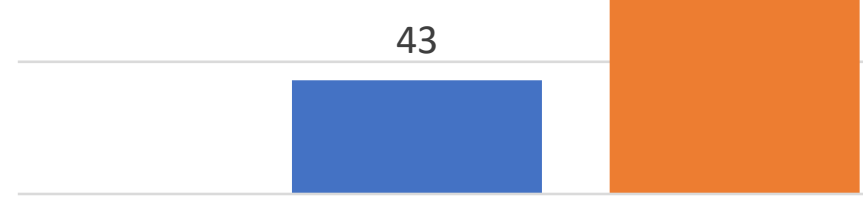

cancer drugs
417

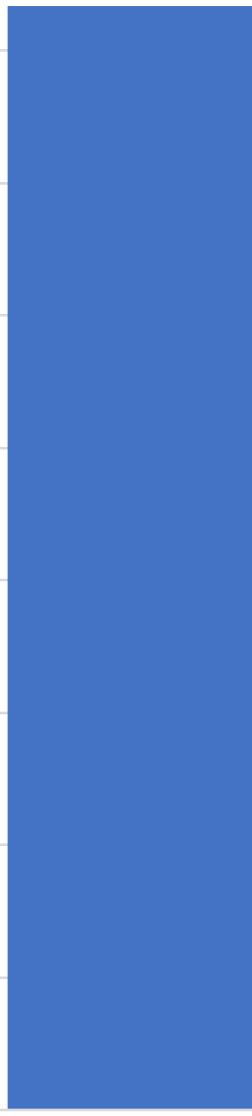

other drugs
242

2005-2014

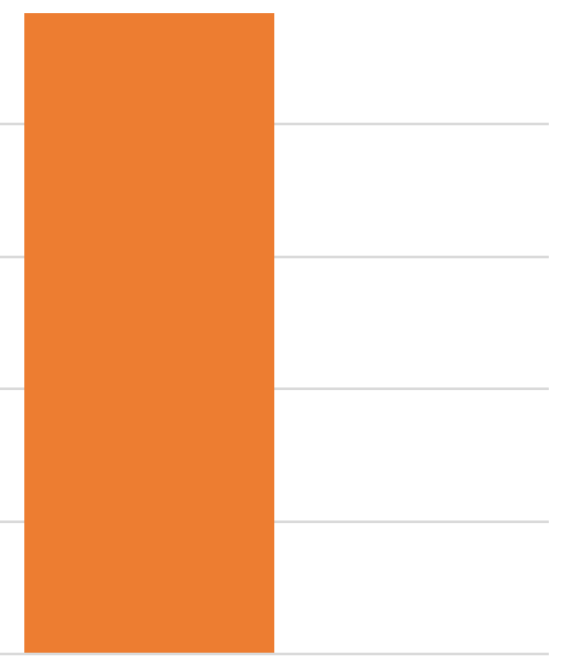

Source: author's calculations based on IMS Health New Product Focus database

"Cancer NMEs" are NMEs in EphMRA/PBIRG Anatomical Classification L (ANTINEOPLASTIC AND IMMUNOMODULATING AGENTS) 
Figure 2

Mean (across 36 countries) number of drug launches, 1982-2015, by cancer site

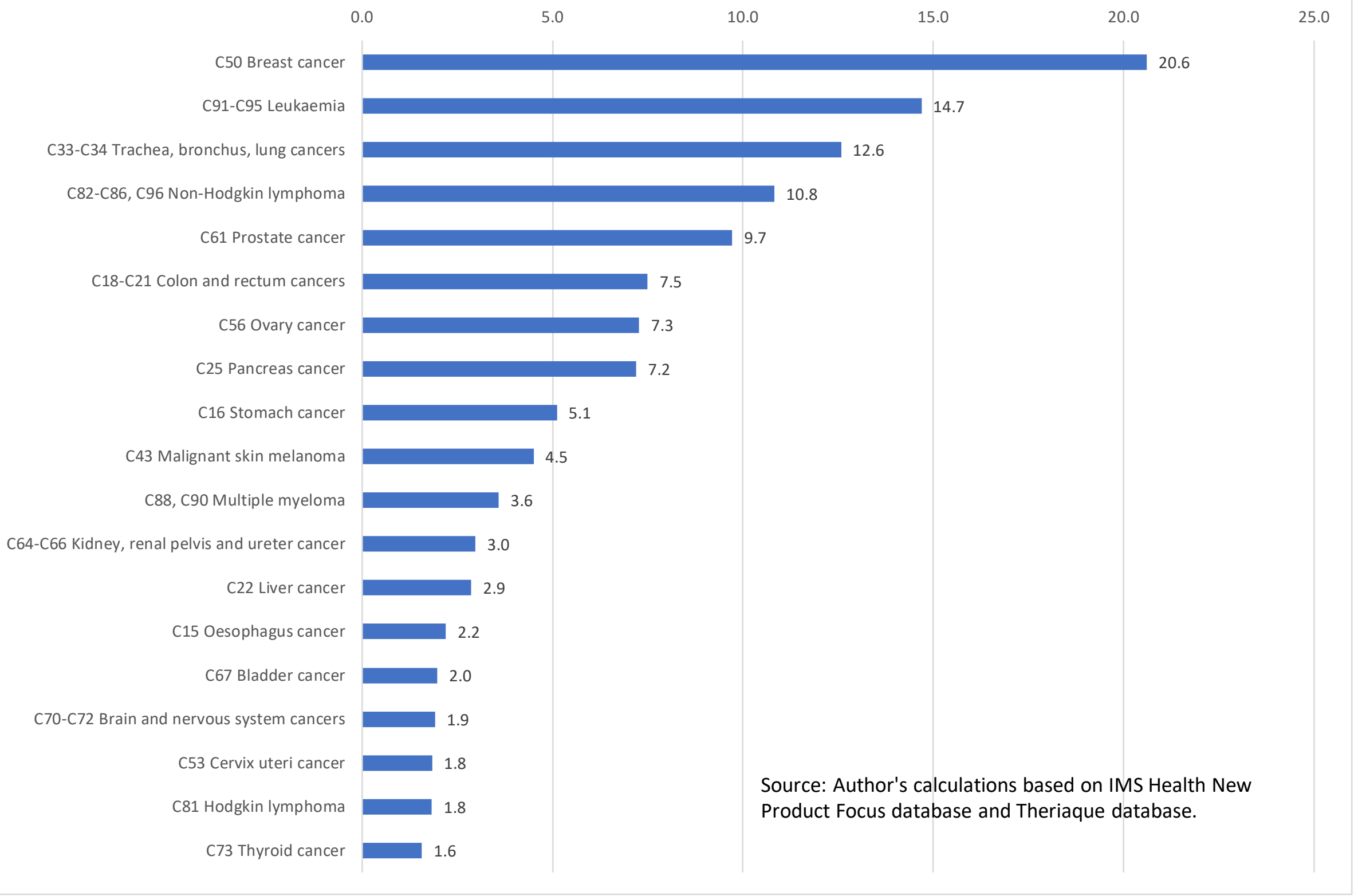


Figure 3

Mean (across 19 cancer sites) number of drug launches, 1982-2015, by country
0.0
1.0
2.0
3.0
4.0
5.0
6.0
7.0

8.0

United States of America (USA)

Austria (AUT)

Germany (DEU)

Finland (FIN)

France (FRA)

Denmark (DNK)

Sweden (SWE)

United Kingdom (GBR)

Switzerland $(\mathrm{CHE})$

Ireland (IRL)

Australia (AUS)

Japan (JPN)

Belgium (BEL)

Italy (ITA)

Netherlands (NLD)

Spain (ESP)

Canada (CAN)

Turkey (TUR)

Mexico (MEX)

Thailand (THA)

Argentina (ARG)

Chile (CHL)

Philippines (PHL)

Brazil (BRA)

Greece (GRC)

South Africa (ZAF)

Singapore (SGP)

Colombia (COL)

Ecuador (ECU)

Egypt (EGY)

Portugal (PRT)

Pakistan (PAK)

Indonesia (IDN) Peru (PER)

Saudi Arabia (SAU)

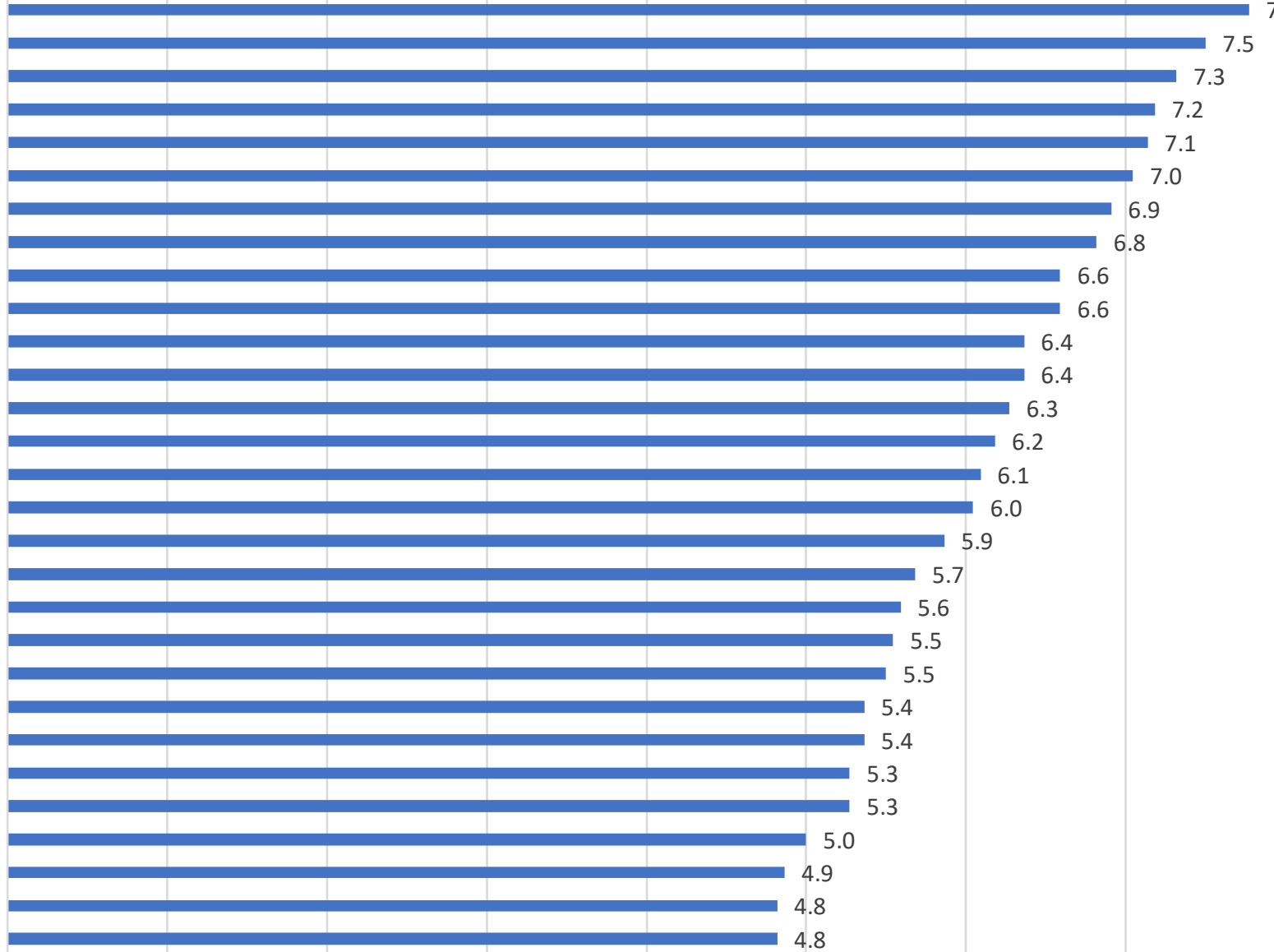

7.8

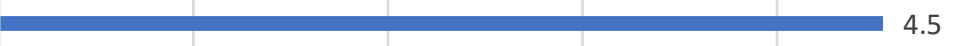

Source: Author's calculations based

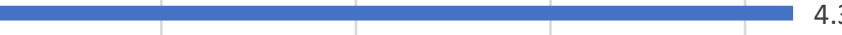

on IMS Health New Product Focus

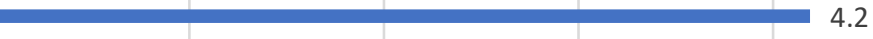

database and Theriaque database. 


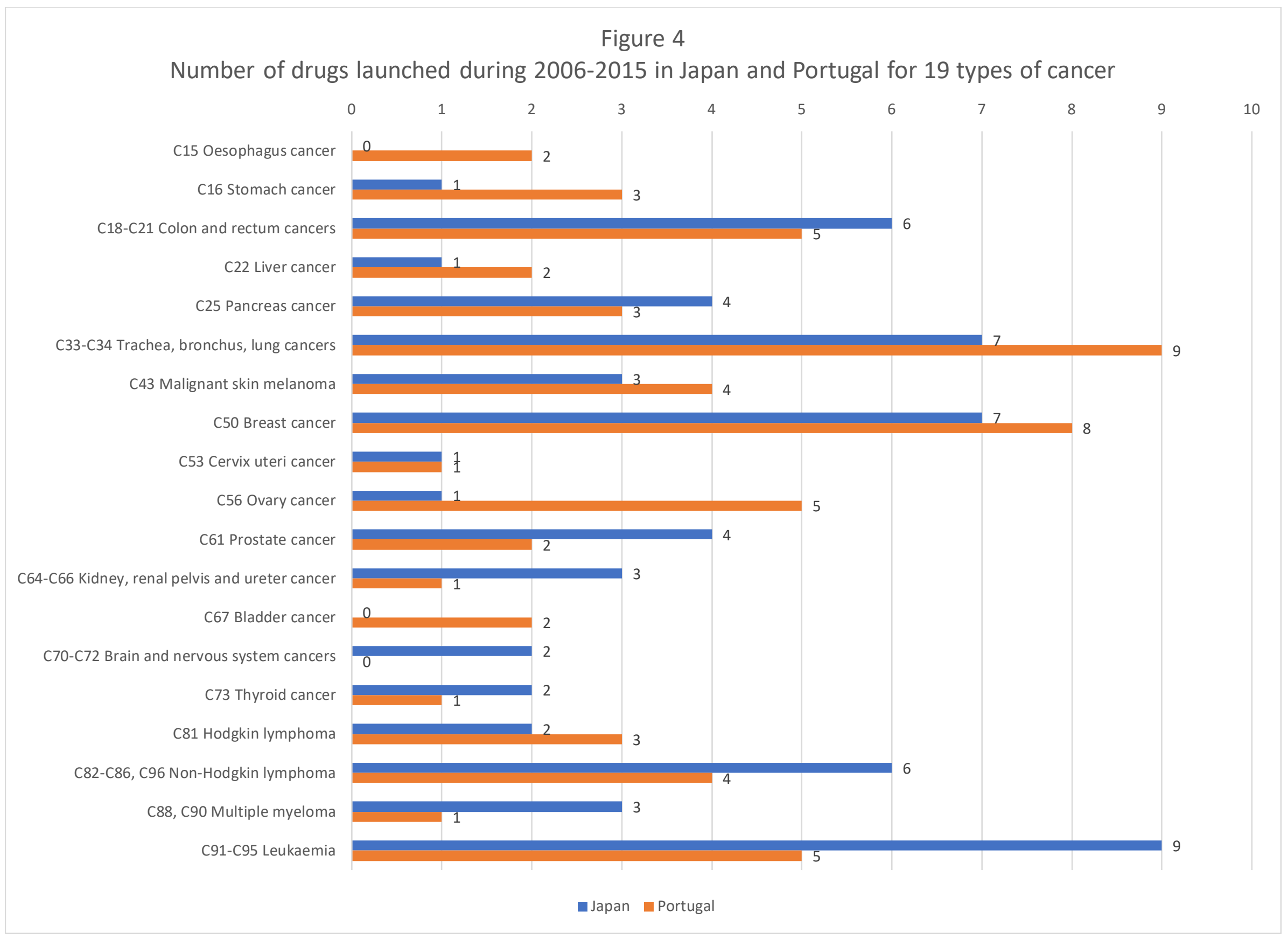


Figure 5

Cancer drug age-utilization profile

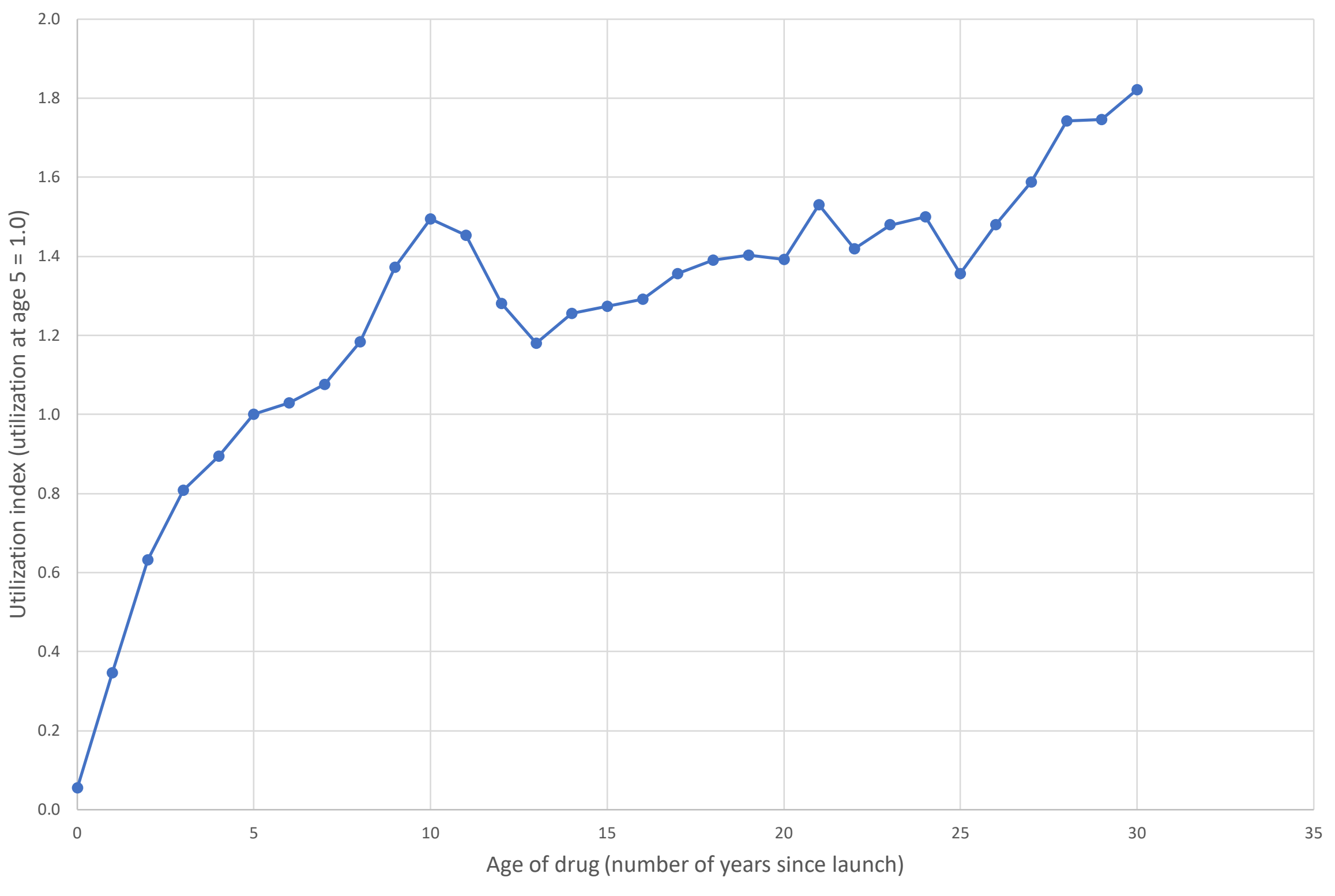


Figure 6

Hypothetical quantity, quality, and impact (= quantity * quality) of a drug when quality increases at a $3 \%$ annual rate with respect to launch year

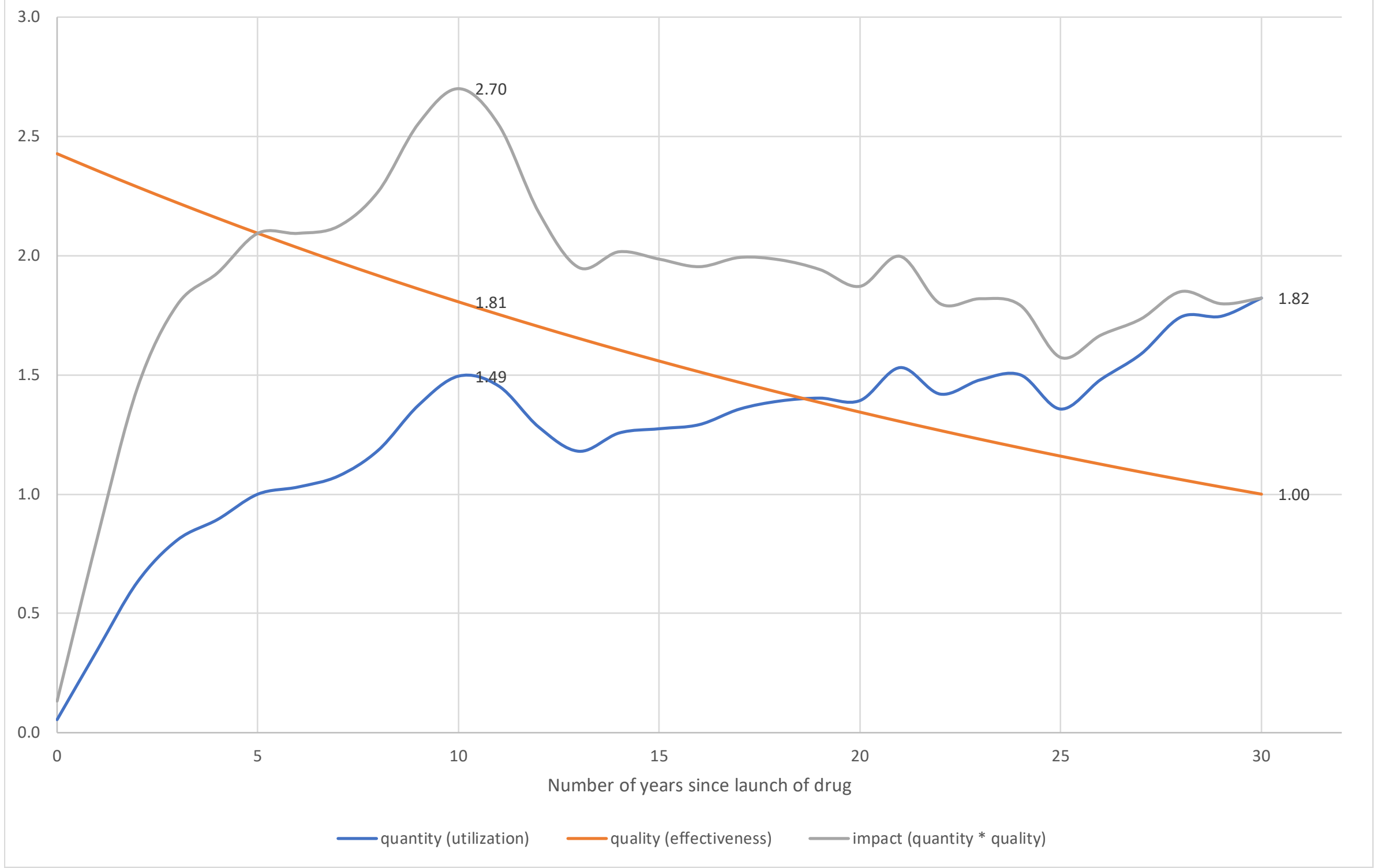


Figure 7

Direct and indirect effects of incidence on life-years lost

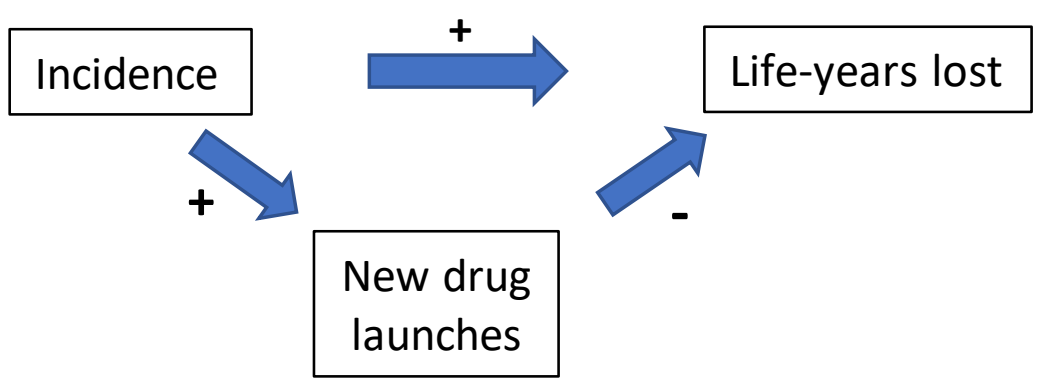


Figure 8

Estimated effects of new drug launches on DALYs and YLL65 in 2015

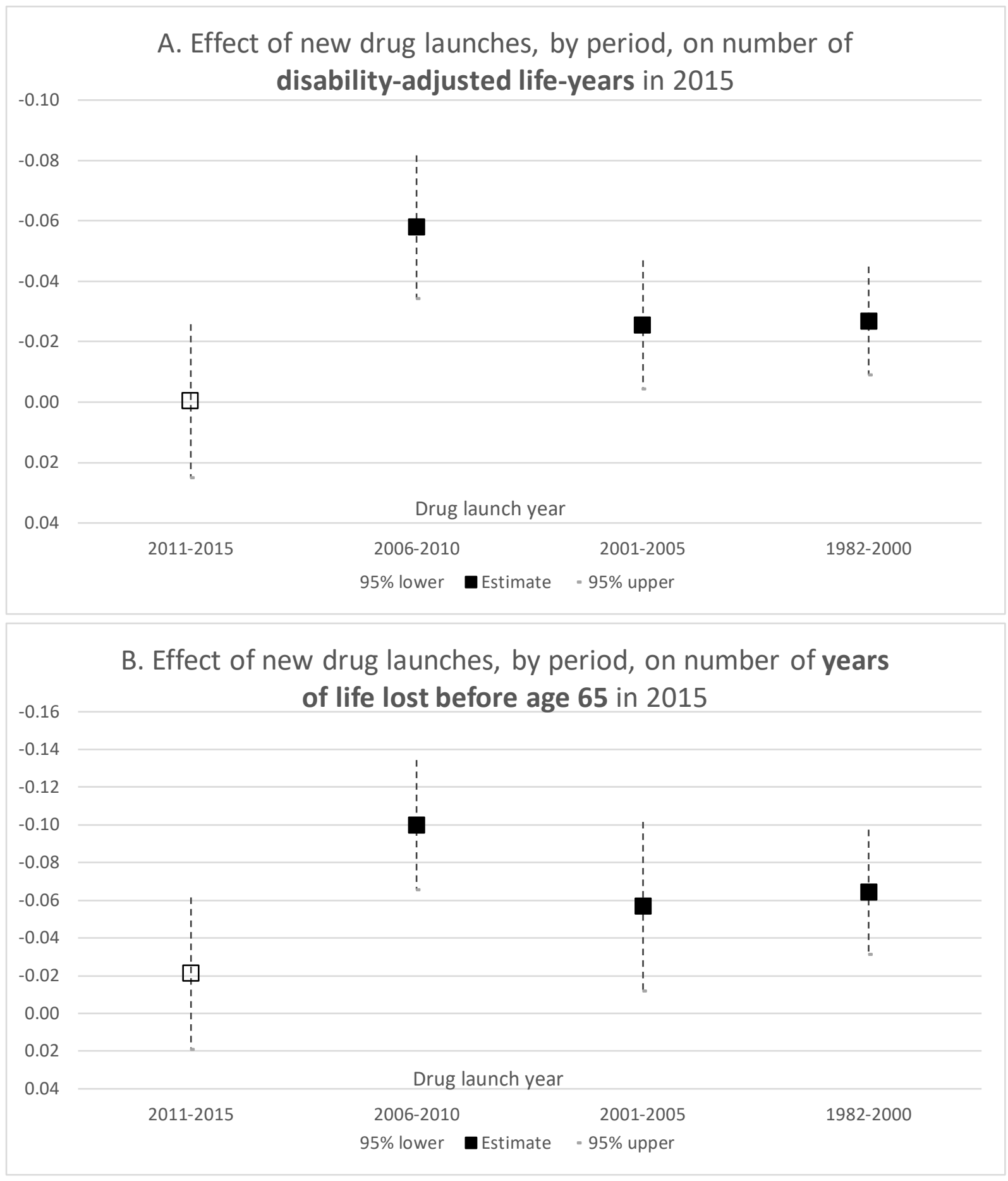

Vertical scale is inverted. Solid markers indicate significant $(P$-value $<.05)$ estimates; hollow markers indicate insignificant estimates. 


\section{Table 1}

Summary statistics, 19 major cancer sites in 36 countries

\begin{tabular}{|l|r|r|r|}
\hline & \multicolumn{1}{|c|}{$\mathbf{2 0 0 5}$} & \multicolumn{1}{c|}{$\mathbf{2 0 1 5}$} & \% change \\
\hline disability-adjusted life years (DALYs) & $68,179,003$ & $76,596,299$ & $12 \%$ \\
\hline $\begin{array}{l}\text { years of life lost, as measured in the WHO Global } \\
\text { Burden of Disease Estimates (YLL) }\end{array}$ & $65,246,858$ & $72,439,899$ & $11 \%$ \\
\hline years lost due to disability (YLD) & $2,932,144$ & $4,156,401$ & $42 \%$ \\
\hline years of life lost before age 75 (YLL75) & $23,398,525$ & $25,137,974$ & $7 \%$ \\
\hline years of life lost before age 65 (YLL65) & $11,163,603$ & $11,545,184$ & $3 \%$ \\
\hline number diagnosed 3 years earlier (CASES) & $4,474,445$ & $5,716,879$ & $28 \%$ \\
\hline
\end{tabular}

Source: Author's calculations based on WHO Global Health Estimates 2015: Disease burden by Cause database (World Health Organization (2016a)); WHO Global Health Estimates 2015: Deaths by Cause database (World Health Organization (2016b)); GLOBOCAN 2002 (Ferlay et al (2004)); and GLOBOCAN 2012 (International Agency for Research on Cancer (2017b)). 
Table 2

Estimates of two-way fixed effects model of life-years lost (eq. (1))

\begin{tabular}{|c|c|c|c|c|c|c|}
\hline Row & arameter & Regressor & Estimate & Std. Err. & $\mathbf{Z}$ & $\operatorname{Pr}>|\mathrm{Z}|$ \\
\hline & \multicolumn{6}{|c|}{ Dependent variable $=\ln ($ DALYS_2015) } \\
\hline 1 & $\beta_{0-4}$ & LAUNCHES_2011_2015 & 0.000 & 0.013 & -0.03 & .9772 \\
\hline 2 & $\beta_{5-9}$ & LAUNCHES_2006_2010 & -0.058 & 0.012 & -4.81 & $<.0001$ \\
\hline 3 & $\beta_{10-14}$ & LAUNCHES_2001_2005 & -0.026 & 0.011 & -2.35 & 0.0187 \\
\hline 4 & $\beta_{15-33}$ & LAUNCHES_1982_2000 & -0.027 & 0.009 & -2.96 & 0.0031 \\
\hline \multirow[t]{2}{*}{5} & 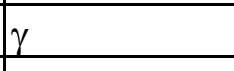 & $\ln ($ CASES_2012) & 0.849 & 0.032 & 26.27 & $<.0001$ \\
\hline & \multicolumn{6}{|c|}{ Dependent variable $=\operatorname{In}\left(Y L L \_2015\right)$} \\
\hline 6 & $\beta_{0-4}$ & LAUNCHES_2011_2015 & 0.003 & 0.014 & 0.23 & 0.8178 \\
\hline 7 & $\beta_{5-9}$ & LAUNCHES_2006_2010 & -0.064 & 0.013 & -5.00 & $<.0001$ \\
\hline 8 & $\beta_{10-14}$ & LAUNCHES_2001_2005 & -0.026 & 0.011 & -2.30 & 0.0217 \\
\hline 9 & $\beta_{15-33}$ & LAUNCHES_1982_2000 & -0.029 & 0.010 & -2.78 & 0.0054 \\
\hline \multirow[t]{2}{*}{10} & . & $\ln (\mathrm{CASES}$ 2012) & 0.844 & 0.037 & 22.85 & $<.0001$ \\
\hline & \multicolumn{6}{|c|}{ Dependent variable $=\ln (Y$ LD_2015) } \\
\hline 11 & $\beta_{0-4}$ & LAUNCHES_2011_2015 & -0.004 & 0.013 & -0.32 & 0.7457 \\
\hline 12 & $\beta_{5-9}$ & LAUNCHES_2006_2010 & -0.017 & 0.015 & -1.11 & 0.2673 \\
\hline 13 & $\beta_{10-14}$ & LAUNCHES_2001_2005 & -0.016 & 0.024 & -0.68 & 0.4963 \\
\hline 14 & $\beta_{15-33}$ & HES_198: & -0.024 & 0.011 & -2.24 & 0.0254 \\
\hline \multirow[t]{2}{*}{15} & $\gamma$ & $\ln ($ CASES_2012) & 6 & .030 & 29.39 & $<.0001$ \\
\hline & \multicolumn{6}{|c|}{ Dependent variable $=\ln ($ YLL75_2015) } \\
\hline 16 & $\beta_{0-4}$ & LAUNCHES_2011_2015 & -0.013 & 0.021 & -0.62 & 0.5381 \\
\hline 17 & $\beta_{5-9}$ & LAUNCHES_2006_2010 & -0.091 & 0.018 & -5.05 & $<.0001$ \\
\hline 18 & $\beta_{10-14}$ & LAUNCHES_2001_2005 & -0.046 & 0.019 & -2.43 & 0.015 \\
\hline 19 & $\beta_{15-33}$ & LAUNCHES_198 & -0.055 & 0.014 & -4.06 & $<.0001$ \\
\hline \multirow[t]{2}{*}{20} & 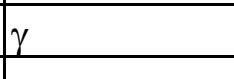 & S_2012) & 0.856 & 0.049 & 17.43 & $<.0001$ \\
\hline & \multicolumn{6}{|c|}{ Dependent variable $=\ln ($ YLL65_2015) } \\
\hline 21 & $\beta_{0-4}$ & LAUNCHES_2011_2015 & -0.021 & 0.021 & -1.03 & 0.3028 \\
\hline 22 & $\beta_{5-9}$ & LAUNCHES_2006_2010 & -0.100 & 0.018 & -5.69 & $<.0001$ \\
\hline 23 & $\beta_{10-14}$ & LAUNCHES_2001_2005 & -0.057 & 0.023 & -2.48 & 0.0132 \\
\hline 24 & $\beta_{15-33}$ & LAUNCHES_1982 & -0.064 & 0.017 & -3.81 & 0.0001 \\
\hline 25 & $\gamma$ & $\ln ($ CASES_2012) & 0.833 & 0.063 & 13.16 & $<.0001$ \\
\hline
\end{tabular}

$\mathrm{N} \approx 684$ (36 countries * 19 cancer sites).

Estimates in bold are statistically significant ( $p$-value $<.05)$.

Disturbances are clustered within cancer sites. 
Table 3

Calculation of pharmaceutical expenditure per life-year gained

\begin{tabular}{|c|c|c|c|c|c|c|}
\hline Column & & 1 & 2 & 3 & 4 & \\
\hline & & \multicolumn{4}{|c|}{ Disease burden measure } & \\
\hline Row & & DALY & YLL & YLL75 & YLL65 & Basis \\
\hline & \multicolumn{6}{|c|}{ Life-years gained calculation } \\
\hline 1 & $\beta_{5-9}$ & -0.058 & -0.064 & -0.091 & -0.100 & Table 2 \\
\hline 2 & weighted mean(LAUNCHES_2006_2010) & 1.505 & 1.487 & 1.532 & 1.607 & $\begin{array}{l}\text { Author's calculations based on IMS New } \\
\text { Product Focus and Theriaque databases }\end{array}$ \\
\hline 3 & $\begin{array}{l}\text { log-change in } 2015 \text { life-years lost due to } \\
\text { LAUNCHES_2006_2010 }\end{array}$ & -0.087 & -0.095 & -0.139 & -0.161 & $(1) *(2)$ \\
\hline 4 & $\begin{array}{l}\text { life-years lost due to all types of cancer in } 36 \text { countries } \\
\text { in } 2015\end{array}$ & $88,108,225$ & $83,467,085$ & $30,255,229$ & $14,451,091$ & World Health Organization (2016a, 2016b). \\
\hline 5 & \begin{tabular}{|l|} 
reduction in 2015 life-years lost due to \\
LAUNCHES_2006_2010
\end{tabular} & $8,035,792$ & $8,280,097$ & $4,509,546$ & $2,520,071$ & $(\exp (-(3))-1) *(4)$ \\
\hline & \multicolumn{6}{|c|}{ Pharmaceutical expenditure calculation } \\
\hline 6 & $\begin{array}{l}\text { global cost (in millions) of oncology therapeutics and } \\
\text { supportive care drugs in 2015, measured at invoice } \\
\text { price levels }\end{array}$ & \multicolumn{4}{|c|}{$\$ 107,000$} & $\begin{array}{l}\text { IMS Institute for Healthcare Informatics } \\
(2016, \text { p. 20) }\end{array}$ \\
\hline 7 & $\begin{array}{l}\text { 36-country share of total pharmaceutical expenditure } \\
\text { in } 2014\end{array}$ & \multicolumn{4}{|c|}{$78 \%$} & $\begin{array}{l}\text { International Federation of Pharmaceutical } \\
\text { Manufacturers \& Associations (2017, } \\
\text { Annex 2) }\end{array}$ \\
\hline 8 & $\begin{array}{l}\text { 36-country cost (in millions) of oncology therapeutics } \\
\text { and supportive care drugs in } 2015\end{array}$ & \multicolumn{4}{|c|}{$\$ 83,076$} & $(6) *(7)$ \\
\hline 9 & $\begin{array}{l}\text { fraction of } 2010 \text { pharma expend. on drugs launched in } \\
\text { country during 2001-2005, } 31 \text { countries }\end{array}$ & \multicolumn{4}{|c|}{$16 \%$} & $\begin{array}{l}\text { Author's calculations based on IMS } \\
\text { MIDAS data }\end{array}$ \\
\hline 10 & $\begin{array}{l}\text { estimated 36-country expenditure (in millions) in } 2015 \\
\text { on cancer drugs launched during 2006-2010 }\end{array}$ & \multicolumn{4}{|c|}{$\$ 13,539$} & $(8) *(9)$ \\
\hline & age group & All ages & All ages & Below 75 & Below 65 & \\
\hline 11 & estimated age group share of cancer drug expenditure & $100 \%$ & $100 \%$ & $76 \%$ & $52 \%$ & $\begin{array}{l}\text { International Agency for Research on } \\
\text { Cancer (2017b) }\end{array}$ \\
\hline \multirow[t]{2}{*}{12} & $\begin{array}{l}\text { estimated } 2015 \text { 36-country expenditure (in millions) } \\
\text { by age group on cancer drugs launched during 2006- } \\
2010\end{array}$ & $\$ 13,539$ & $\$ 13,539$ & $\$ 10,264$ & $\$ 7,106$ & $(10) *(11)$ \\
\hline & \multicolumn{6}{|c|}{ Pharmaceutical expenditure per life-year gained calculation } \\
\hline 13 & pharmaceutical expenditure per life-year gained & $\$ 1,685$ & $\$ 1,635$ & $\$ 2,276$ & $\$ 2,820$ & $(12) /(5)$ \\
\hline
\end{tabular}


Appendix Table 1

Number of drugs launched during 2006-2015, by country and cancer site

\begin{tabular}{|c|c|c|c|c|c|c|c|c|c|c|c|c|c|c|c|c|c|c|c|c|}
\hline Country & 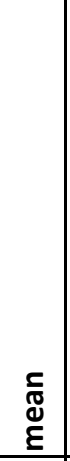 & 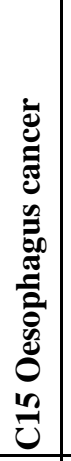 & 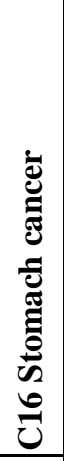 & 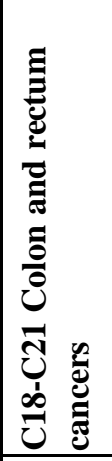 & 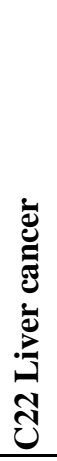 & 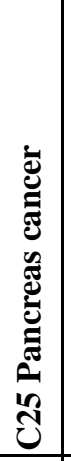 & 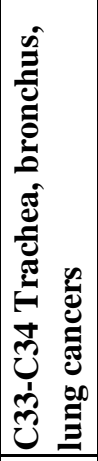 & 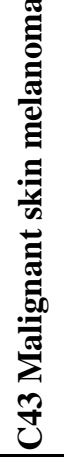 & 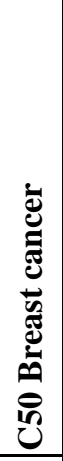 & 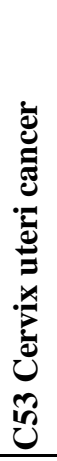 & 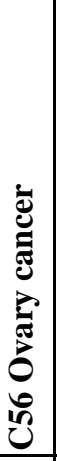 & 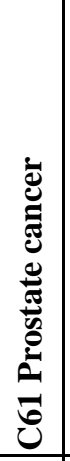 & 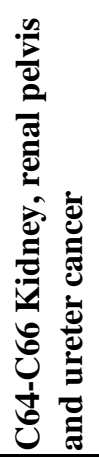 & 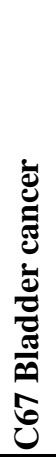 & 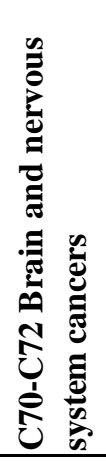 & 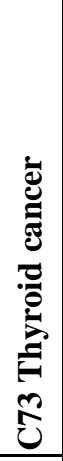 & 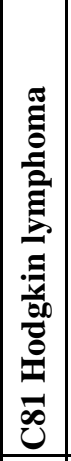 & 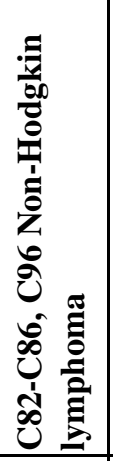 & 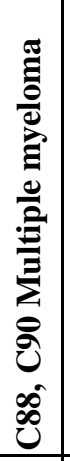 & 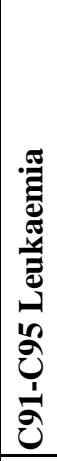 \\
\hline Argentina & 1.6 & 1 & 0 & 3 & 0 & 2 & 5 & 0 & 3 & 1 & 1 & 3 & 2 & 0 & 1 & 1 & 0 & 3 & 1 & 4 \\
\hline Australia & 2.9 & 0 & 2 & 5 & 1 & 2 & 5 & 5 & 7 & 0 & 0 & 4 & 1 & 0 & 1 & 1 & 1 & 7 & 3 & 10 \\
\hline Austria & 3.8 & 0 & 2 & 6 & 2 & 4 & 7 & 6 & 4 & 0 & 2 & 4 & 2 & 1 & 1 & 3 & 2 & 10 & 4 & 13 \\
\hline Belgium & 3.4 & 0 & 0 & 7 & 2 & 3 & 8 & 1 & 6 & 2 & 4 & 4 & 2 & 1 & 1 & 2 & 1 & 8 & 3 & 9 \\
\hline Brazil & 2.2 & 0 & 1 & 4 & 1 & 4 & 3 & 2 & 6 & 1 & 1 & 3 & 2 & 0 & 0 & 1 & 1 & 4 & 2 & 6 \\
\hline Canada & 1.8 & 0 & 0 & 5 & 1 & 2 & 1 & 2 & 3 & 0 & 1 & 2 & 1 & 0 & 0 & 1 & 1 & 5 & 1 & 8 \\
\hline Chile & 2.9 & 0 & 1 & 3 & 2 & 4 & 7 & 2 & 9 & 2 & 4 & 4 & 2 & 1 & 1 & 1 & 0 & 5 & 3 & 4 \\
\hline Colombia & 1.7 & 0 & 0 & 2 & 1 & 2 & 5 & 1 & 5 & 2 & 2 & 1 & 2 & 0 & 0 & 1 & 0 & 3 & 2 & 4 \\
\hline Denmark & 3.1 & 0 & 1 & 5 & 1 & 2 & 6 & 5 & 3 & 0 & 1 & 4 & 2 & 0 & 1 & 3 & 2 & 9 & 3 & 11 \\
\hline Ecuador & 1.2 & 0 & 0 & 2 & 1 & 2 & 2 & 0 & 4 & 0 & 1 & 0 & 1 & 0 & 0 & 1 & 0 & 3 & 2 & 4 \\
\hline Egypt & 3.0 & 1 & 3 & 5 & 2 & 3 & 7 & 0 & 11 & 2 & 4 & 5 & 1 & 1 & 1 & 1 & 0 & 2 & 1 & 7 \\
\hline Finland & 3.2 & 0 & 1 & 4 & 1 & 2 & 7 & 6 & 3 & 0 & 1 & 4 & 2 & 0 & 1 & 3 & 2 & 9 & 3 & 11 \\
\hline France & 3.1 & 1 & 2 & 4 & 1 & 2 & 6 & 4 & 5 & 0 & 1 & 5 & 1 & 0 & 1 & 2 & 1 & 8 & 3 & 11 \\
\hline Germany & 3.0 & 0 & 0 & 3 & 1 & 2 & 5 & 5 & 3 & 0 & 1 & 4 & 2 & 0 & 1 & 3 & 2 & 10 & 3 & 12 \\
\hline Greece & 1.2 & 0 & 0 & 2 & 1 & 2 & 2 & 0 & 1 & 0 & 0 & 2 & 1 & 0 & 0 & 1 & 0 & 3 & 2 & 6 \\
\hline Indonesia & 1.1 & 0 & 0 & 2 & 1 & 3 & 2 & 0 & 4 & 0 & 0 & 1 & 1 & 0 & 0 & 1 & 0 & 1 & 1 & 4 \\
\hline Ireland & 3.3 & 0 & 1 & 3 & 2 & 3 & 7 & 4 & 6 & 0 & 3 & 4 & 2 & 1 & 1 & 2 & 2 & 9 & 3 & 9 \\
\hline Italy & 1.8 & 0 & 0 & 2 & 1 & 2 & 2 & 2 & 3 & 0 & 1 & 2 & 0 & 0 & 0 & 1 & 1 & 7 & 2 & 9 \\
\hline Japan & 3.3 & 0 & 1 & 6 & 1 & 4 & 7 & 3 & 7 & 1 & 1 & 4 & 3 & 0 & 2 & 2 & 2 & 6 & 3 & 9 \\
\hline Mexico & 2.2 & 0 & 0 & 2 & 0 & 4 & 3 & 2 & 5 & 1 & 2 & 3 & 1 & 0 & 1 & 1 & 1 & 7 & 3 & 5 \\
\hline Netherlands & 1.8 & 0 & 1 & 3 & 1 & 1 & 2 & 3 & 3 & 0 & 0 & 4 & 1 & 0 & 0 & 2 & 0 & 3 & 3 & 7 \\
\hline Pakistan & 0.9 & 0 & 0 & 2 & 1 & 3 & 3 & 0 & 4 & 1 & 1 & 0 & 1 & 0 & 0 & 1 & 0 & 0 & 0 & 1 \\
\hline Peru & 2.1 & 1 & 2 & 2 & 2 & 2 & 2 & 1 & 8 & 1 & 2 & 4 & 0 & 1 & 0 & 1 & 1 & 3 & 1 & 6 \\
\hline Philippines & 2.3 & 0 & 1 & 4 & 1 & 4 & 6 & 0 & 6 & 2 & 3 & 2 & 2 & 0 & 1 & 1 & 0 & 4 & 2 & 4 \\
\hline Portugal & 3.2 & 2 & 3 & 5 & 2 & 3 & 9 & 4 & 8 & 1 & 5 & 2 & 1 & 2 & 0 & 1 & 3 & 4 & 1 & 5 \\
\hline Saudi & 1.8 & 0 & 2 & 1 & 1 & 2 & 3 & 0 & 7 & 1 & 1 & 3 & 0 & 0 & 1 & 1 & 0 & 5 & 1 & 5 \\
\hline Singapore & 2.1 & 0 & 0 & 2 & 2 & 4 & 4 & 1 & 6 & 0 & 2 & 3 & 1 & 1 & 1 & 1 & 1 & 4 & 1 & 5 \\
\hline South & 2.8 & 1 & 1 & 5 & 2 & 3 & 5 & 2 & 6 & 1 & 4 & 5 & 1 & 1 & 0 & 1 & 1 & 6 & 3 & 6 \\
\hline Spain & 2.8 & 1 & 1 & 3 & 1 & 2 & 6 & 3 & 6 & 1 & 2 & 5 & 1 & 0 & 1 & 1 & 1 & 6 & 2 & 10 \\
\hline Sweden & 3.2 & 1 & 2 & 4 & 1 & 2 & 6 & 5 & 5 & 0 & 1 & 4 & 2 & 0 & 1 & 3 & 2 & 9 & 2 & 11 \\
\hline Switzerland & 2.6 & 0 & 0 & 3 & 1 & 3 & 4 & 4 & 5 & 0 & 1 & 4 & 1 & 0 & 1 & 3 & 1 & 7 & 2 & 10 \\
\hline Thailand & 1.8 & 0 & 0 & 3 & 1 & 2 & 1 & 1 & 5 & 0 & 1 & 3 & 1 & 0 & 1 & 1 & 0 & 5 & 3 & 6 \\
\hline Turkey & 2.1 & 0 & 0 & 5 & 1 & 3 & 3 & 2 & 5 & 1 & 2 & 2 & 2 & 0 & 1 & 1 & 0 & 4 & 1 & 7 \\
\hline UK & 2.7 & 0 & 1 & 3 & 1 & 3 & 6 & 3 & 4 & 0 & 1 & 4 & 1 & 0 & 1 & 2 & 1 & 8 & 2 & 10 \\
\hline USA & 3.4 & 0 & 1 & 4 & 0 & 3 & 6 & 7 & 5 & 0 & 1 & 4 & 2 & 0 & 2 & 2 & 2 & 10 & 5 & 11 \\
\hline Venezuela & 0.1 & 0 & 0 & 0 & 0 & 0 & 0 & 0 & 2 & 0 & 0 & 0 & 0 & 0 & 0 & 0 & 0 & 0 & 0 & \begin{tabular}{|c|}
0 \\
\end{tabular} \\
\hline
\end{tabular}


Appendix Table 2

Post-1981 Drugs Indicated for Different Types of Cancer

\begin{tabular}{|c|c|c|c|c|c|c|c|c|c|c|c|c|c|c|c|c|c|c|c|}
\hline & 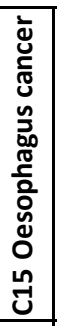 & 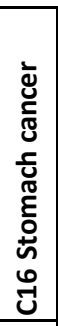 & 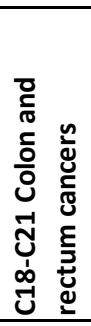 & 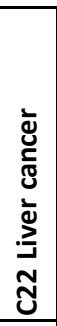 & 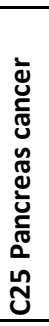 & 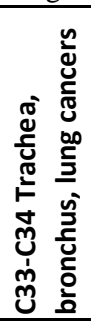 & 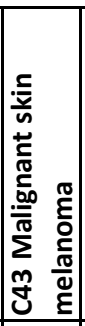 & 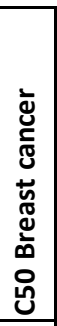 & 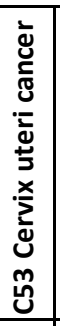 & 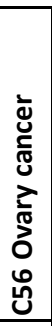 & 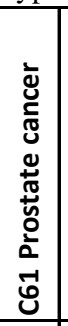 & 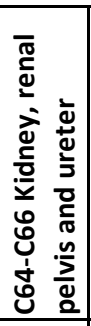 & 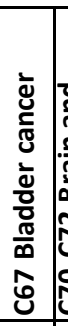 & 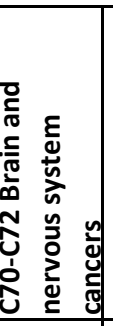 & 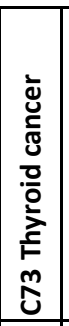 & 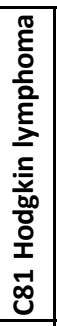 & 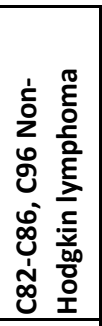 & 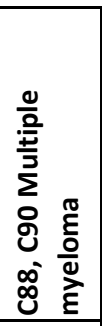 & 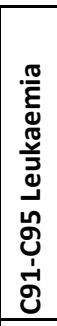 \\
\hline No. of drugs & 3 & 6 & 10 & 3 & 9 & 18 & 10 & 26 & 2 & 8 & 12 & 4 & 2 & 4 & 3 & 3 & 19 & 7 & 27 \\
\hline AFATINIB & & & & & & 1 & & & & & & & & & & & & & \\
\hline AFLIBERCEPT & & & 1 & & & & & & & & & & & & & & & & \\
\hline ALEMTUZUMAB & & & & & & & & & & & & & & & & & & & 1 \\
\hline AMIFOSTINE & & & & & & & & & & 1 & & & & & & & & & \\
\hline AMSACRINE & & & & & & & & & & & & & & & & & & & 1 \\
\hline ANASTROZOLE & & & & & & & & 1 & & & & & & & & & & & \\
\hline ARSENIC TRIOXIDE & & & & & & & & & & & & & & & & & & & 1 \\
\hline AZACITIDINE & & & & & & & & & & & & & & & & & & & 1 \\
\hline BEVACIZUMAB & & & 1 & & & 1 & & 1 & 1 & 1 & & 1 & & & & & & & \\
\hline BEXAROTENE & & & & & & & & & & & & & & & & & 1 & & \\
\hline BICALUTAMIDE & & & & & & & & & & & 1 & & & & & & & & \\
\hline BLINATUMOMAB & & & & & & & & & & & & & & & & & & & 1 \\
\hline BORTEZOMIB & & & & & & & & & & & & & & & & & 1 & 1 & \\
\hline BOSUTINIB & & & & & & & & & & & & & & & & & & & 1 \\
\hline $\begin{array}{l}\text { BRENTUXIMAB } \\
\text { VEDOTIN }\end{array}$ & & & & & & & & & & & & & & & & 1 & 1 & & \\
\hline BUSERELIN & & & & & & & & & & & 1 & & & & & & & & \\
\hline CABAZITAXEL & & & & & & & & & & & 1 & & & & & & & & \\
\hline CAPECITABINE & & 1 & 1 & & & & & 1 & & & & & & & & & & & \\
\hline CARBOPLATIN & & & & & & 1 & & & & 1 & & & & & & & & & \\
\hline CERITINIB & & & & & & 1 & & & & & & & & & & & & & \\
\hline CETUXIMAB & & & 1 & & & & & & & & & & & & & & & & \\
\hline CLADRIBINE & & & & & & & & & & & & & & & & & & & 1 \\
\hline CLOFARABINE & & & & & & & & & & & & & & & & & & & 1 \\
\hline COBIMETINIB & & & & & & & 1 & & & & & & & & & & & & \\
\hline CRIZOTINIB & & & & & & 1 & & & & & & & & 1 & & & 1 & & \\
\hline DABRAFENIB & & & & & & & 1 & & & & & & & & & & & & \\
\hline DARATUMUMAB & & & & & & & & & & & & & & & & & & 1 & \\
\hline DASATINIB & & & & & & & & & & & & & & & & & & & 1 \\
\hline DECITABINE & & & & & & & & & & & & & & & & & & & 1 \\
\hline DEGARELIX & & & & & & & & & & & 1 & & & & & & & & \\
\hline DENILEUKIN DIFTITOX & & & & & & & & & & & & & & & & & 1 & & \\
\hline DENOSUMAB & & & & & & & & & & & 1 & & & & & & & & \\
\hline DINUTUXIMAB & & & & & & & & & & & & & & 1 & & & & & \\
\hline DOCETAXEL & 1 & 1 & & & & 1 & & 1 & & & 1 & & & & & & & & \\
\hline ENZALUTAMIDE & & & & & & & & & & & 1 & & & & & & & & \\
\hline
\end{tabular}


Appendix Table 2

Post-1981 Drugs Indicated for Different Types of Cancer

\begin{tabular}{|c|c|c|c|c|c|c|c|c|c|c|c|c|c|c|c|c|c|c|c|}
\hline & 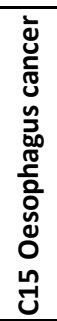 & 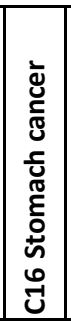 & 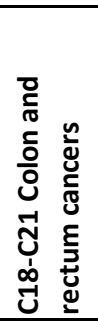 & 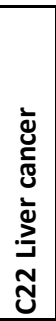 & 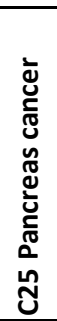 & 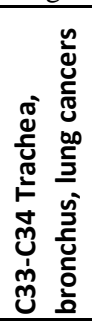 & 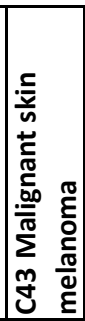 & 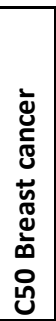 & 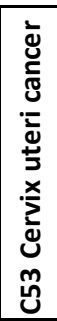 & 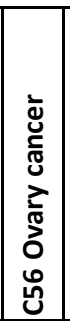 & 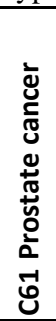 & 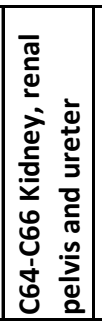 & 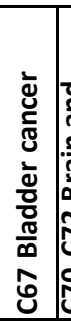 & 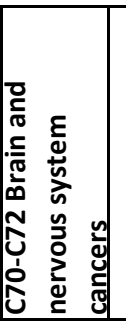 & 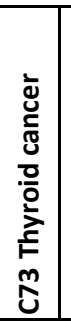 & 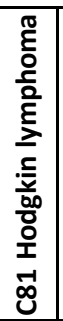 & 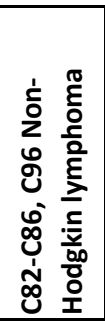 & 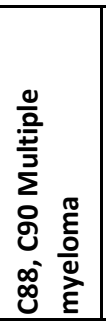 & 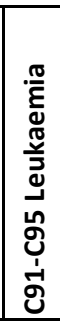 \\
\hline EPIRUBICIN & 1 & 1 & & 1 & 1 & 1 & & 1 & & 1 & & & 1 & & & 1 & 1 & & \\
\hline ERIBULIN & & & & & & & & 1 & & & & & & & & & & & \\
\hline ERLOTINIB & & & & & 1 & 1 & & & & & & & & & & & & & \\
\hline EVEROLIMUS & & & & & 1 & & & 1 & & & & & & & & & & & \\
\hline EXEMESTANE & & & & & & & & 1 & & & & & & & & & & & \\
\hline FLUDARABINE & & & & & & & & & & & & & & & & & & & 1 \\
\hline FLUTAMIDE & & & & & & & & & & & 1 & & & & & & & & \\
\hline FORMESTANE & & & & & & & & 1 & & & & & & & & & & & \\
\hline FOTEMUSTINE & & & & & & & 1 & & & & & & & 1 & & & & & \\
\hline \begin{tabular}{|l} 
FULVESTRANT \\
\end{tabular} & & & & & & & & 1 & & & & & & & & & & & \\
\hline GADOBENIC ACID & & & & & & & & 1 & & & & & & & & & & & \\
\hline GEFITINIB & & & & & & 1 & & & & & & & & & & & & & \\
\hline GEMCITABINE & & & & 1 & 1 & 1 & & 1 & & 1 & & & 1 & & & & & & \\
\hline \begin{tabular}{|l} 
GOSERELIN \\
\end{tabular} & & & & & & & & 1 & & & 1 & & & & & & & & \\
\hline IBANDRONIC ACID & & & & & & & & 1 & & & & & & & & & & & \\
\hline IBRUTINIB & & & & & & & & & & & & & & & & & 1 & 1 & 1 \\
\hline IDARUBICIN & & & & & & & & & & & & & & & & & & & 1 \\
\hline IDELALISIB & & & & & & & & & & & & & & & & & 1 & & 1 \\
\hline IMATINIB & & & & & & & & & & & & & & & & & & & 1 \\
\hline INTERFERON ALFA-2A & & & & & & & 1 & & & & & 1 & & & & & 1 & & 1 \\
\hline INTERFERON ALFA-2B & & & & & & & 1 & & & & & & & & & & 1 & 1 & 1 \\
\hline IPILIMUMAB & & & & & & & 1 & & & & & & & & & & & & \\
\hline IRINOTECAN & & & 1 & & & & & & & & & & & & & & & & \\
\hline LAPATINIB & & & & & & & & 1 & & & & & & & & & & & \\
\hline LENALIDOMIDE & & & & & & & & & & & & & & & & & 1 & 1 & \\
\hline \begin{tabular}{|l|} 
LENVATINIB \\
\end{tabular} & & & & & & & & & & & & & & & 1 & & & & \\
\hline LETROZOLE & & & & & & & & 1 & & & & & & & & & & & \\
\hline LEUPRORELIN & & & & & & & & 1 & & & 1 & & & & & & & & \\
\hline MILTEFOSINE & & & & & & & & 1 & & & & & & & & & & & \\
\hline MITOXANTRONE & & & & & & & & 1 & & & 1 & & & & & & 1 & & 1 \\
\hline NELARABINE & & & & & & & & & & & & & & & & & 1 & & 1 \\
\hline NILOTINIB & & & & & & & & & & & & & & & & & & & 1 \\
\hline \begin{tabular}{|l|} 
NILUTAMIDE \\
\end{tabular} & & & & & & & & & & & 1 & & & & & & & & \\
\hline \begin{tabular}{|l|} 
NIVOLUMAB \\
\end{tabular} & & & & & & 1 & 1 & & & & & 1 & & & & 1 & & & \\
\hline OBINUTUZUMAB & & & & & & & & & & & & & & & & & 1 & & 1 \\
\hline OCTREOTIDE & & 1 & & & 1 & & & & & & & & & & & & & & \\
\hline OFATUMUMAB & & & & & & & & & & & & & & & & & & & 1 \\
\hline
\end{tabular}


Appendix Table 2

Post-1981 Drugs Indicated for Different Types of Cancer

\begin{tabular}{|c|c|c|c|c|c|c|c|c|c|c|c|c|c|c|c|c|c|c|c|}
\hline & 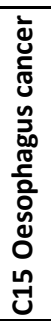 & 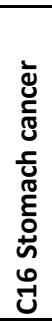 & 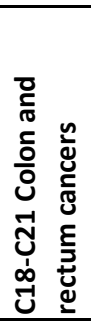 & 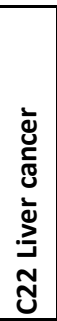 & 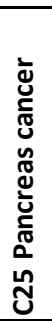 & 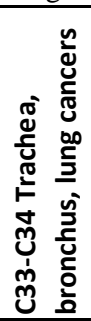 & 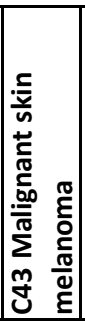 & 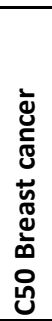 & 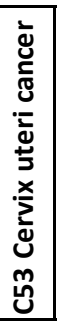 & 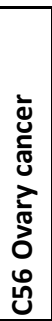 & 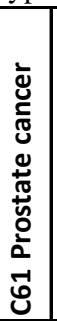 & 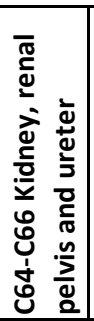 & 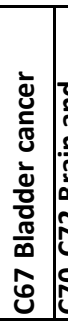 & 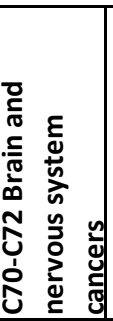 & 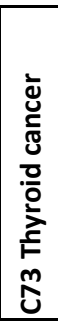 & 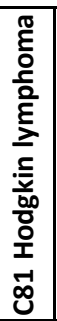 & 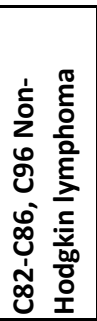 & 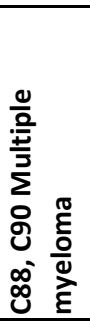 & 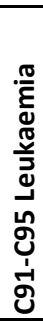 \\
\hline OXALIPLATIN & & & 1 & & & & & & & & & & & & & & & & \\
\hline PACLITAXEL & & & & & 1 & 1 & & 1 & & 1 & & & & & & & & & \\
\hline PANITUMUMAB & & & 1 & & & & & & & & & & & & & & & & \\
\hline PANOBINOSTAT & & & & & & & & & & & & & & & & & & 1 & \\
\hline PASIREOTIDE & & & & & 1 & & & & & & & & & & & & & & \\
\hline PAZOPANIB & & & & & & & & & & & & 1 & & & & & & & \\
\hline PEGASPARGASE & & & & & & & & & & & & & & & & & & & 1 \\
\hline PEMBROLIZUMAB & & & & & & 1 & 1 & & & & & & & & & & & & \\
\hline PEMETREXED & & & & & & 1 & & & & & & & & & & & & & \\
\hline PENTOSTATIN & & & & & & & & & & & & & & & & & & & 1 \\
\hline PERTUZUMAB & & & & & & & & 1 & & & & & & & & & & & \\
\hline PIRARUBICIN & & & & & & & & 1 & & & & & & & & & & & \\
\hline PIXANTRONE & & & & & & & & & & & & & & & & & 1 & & \\
\hline PLERIXAFOR & & & & & & & & & & & & & & & & & 1 & 1 & \\
\hline PONATINIB & & & & & & & & & & & & & & & & & & & 1 \\
\hline PORFIMER SODIUM & 1 & & & & & 1 & & & & & & & & & & & & & \\
\hline RALTITREXED & & & 1 & & & & & & & & & & & & & & & & \\
\hline RAMUCIRUMAB & & 1 & 1 & & & 1 & & & & & & & & & & & & & \\
\hline REGORAFENIB & & & 1 & & & & & & & & & & & & & & & & \\
\hline RITUXIMAB & & & & & & & & & & & & & & & & & 1 & & 1 \\
\hline ROMIDEPSIN & & & & & & & & & & & & & & & & & 1 & & \\
\hline SORAFENIB & & & & 1 & & & & & & & & & & & 1 & & & & \\
\hline STREPTOZOCIN & & & & & 1 & & & & & & & & & & & & & & \\
\hline SUNITINIB & & & & & 1 & & & & & & & & & & & & & & \\
\hline TEMOZOLOMIDE & & & & & & & & & & & & & & 1 & & & & & \\
\hline TEMSIROLIMUS & & & & & & & & & & & & & & & & & 1 & & \\
\hline TOPOTECAN & & & & & & 1 & & & 1 & 1 & & & & & & & & & \\
\hline TOREMIFENE & & & & & & & & 1 & & & & & & & & & & & \\
\hline TRABECTEDIN & & & & & & & & & & 1 & & & & & & & & & \\
\hline TRAMETINIB & & & & & & & 1 & & & & & & & & & & & & \\
\hline TRASTUZUMAB & & 1 & & & & & & 1 & & & & & & & & & & & \\
\hline $\begin{array}{l}\text { TRASTUZUMAB } \\
\text { EMTANSINE }\end{array}$ & & & & & & & & 1 & & & & & & & & & & & \\
\hline VANDETANIB & & & & & & & & & & & & & & & 1 & & & & \\
\hline VEMURAFENIB & & & & & & & 1 & & & & & & & & & & & & \\
\hline VINORELBINE & & & & & & 1 & & 1 & & & & & & & & & & & \\
\hline ZORUBICIN & & & & & & & & & & & & & & & & & & & 1 \\
\hline
\end{tabular}


Appendix Table 3

Drug launch years

\begin{tabular}{|c|c|c|c|c|c|c|c|c|c|c|c|c|c|c|c|c|c|c|}
\hline & 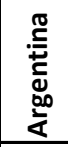 & $\begin{array}{l}\frac{\pi}{\pi} \\
\frac{\pi}{2} \\
\frac{n}{2} \\
\frac{2}{4}\end{array}$ & 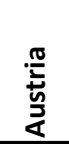 & $\frac{\underline{E}}{\frac{5}{50}}$ & $\begin{array}{l}\overline{\bar{N}} \\
\frac{\mathbb{D}}{0} \\
\end{array}$ & 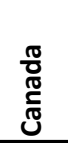 & $\frac{0}{\frac{Z}{c}}$ & $\begin{array}{l}\frac{.0}{0} \\
\text { 등 } \\
\text { 응 }\end{array}$ & 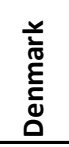 & $\begin{array}{l}\text { 흉 } \\
\frac{\pi}{3} \\
\text { ü }\end{array}$ & 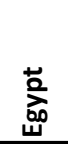 & $\begin{array}{l}\frac{5}{\pi} \\
\text { ñ } \\
\text { ñ }\end{array}$ & 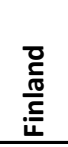 & 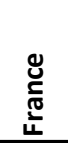 & 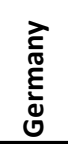 & 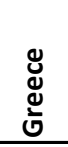 & 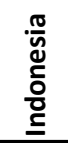 & 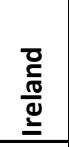 \\
\hline AFATINIB & & 2014 & & 2014 & & & 2014 & & 2013 & & & 2014 & 2013 & 2014 & & & & 2014 \\
\hline AFLIBERCEPT & & 2012 & 2013 & 2013 & 2013 & 2013 & 2013 & & 2012 & 2014 & & 2013 & 2012 & 2013 & 2012 & 2014 & 2014 & 2013 \\
\hline ALEMTUZUMAB & 2005 & 2007 & 2001 & 2003 & & 2006 & & & 2001 & & & 2002 & 2002 & 2002 & 2001 & & 2007 & 2001 \\
\hline AMIFOSTINE & 1995 & 1998 & 1995 & 1999 & 1997 & 1996 & & 1998 & 1996 & 1998 & & 1999 & 1996 & 1995 & 1995 & 1997 & 1998 & \\
\hline AMSACRINE & & 1985 & & 2014 & & & & & 1985 & & & & 1986 & 2004 & 1985 & & & 1997 \\
\hline ANASTROZOLE & 1997 & 1997 & 1996 & 1997 & 1997 & 1996 & 2000 & 1998 & 1997 & 2001 & 2004 & 1997 & 1996 & 1997 & 1996 & 1998 & 1998 & 1996 \\
\hline ARSENIC TRIOXIDE & & & 2002 & 2005 & & & & & & & & 2004 & & 2003 & & 2007 & & \\
\hline AZACITIDINE & 2009 & 2009 & 2009 & & 2011 & 2013 & 2011 & 2011 & 2009 & 2012 & 2015 & 2009 & 2009 & 2009 & 2009 & 2010 & & 2009 \\
\hline BEVACIZUMAB & 2006 & 2005 & 2005 & 2007 & 2006 & 2005 & 2006 & 2006 & 2005 & 2005 & 2011 & 2005 & 2005 & 2005 & 2005 & 2005 & 2005 & 2005 \\
\hline BEXAROTENE & & & 2002 & 2007 & & & & & 2005 & 2007 & & 2002 & 2005 & 2002 & 2002 & 2004 & & 2002 \\
\hline \begin{tabular}{|l|} 
BICALUTAMIDE \\
\end{tabular} & 1996 & 1996 & 1997 & 1997 & 1996 & 1996 & 1999 & 1998 & 1996 & 2001 & 2004 & 1996 & 1995 & 1998 & 1996 & 1997 & & 1995 \\
\hline \multicolumn{19}{|l|}{ BLINATUMOMAB } \\
\hline BORTEZOMIB & 2005 & 2007 & 2004 & 2005 & 2006 & 2005 & 2006 & 2006 & 2004 & 2007 & 2011 & 2004 & 2004 & 2004 & 2004 & 2006 & 2006 & 2004 \\
\hline BOSUTINIB & & & 2013 & & & & & & 2013 & & & & & & 2013 & & & \\
\hline BRENTUXIMAB VE & & 2011 & 2012 & 2014 & 2015 & 2013 & & & 2012 & & & 2014 & 2012 & 2013 & 2012 & & & 2013 \\
\hline BUSERELIN & 1990 & & 1987 & 1986 & 1993 & 1988 & & 1992 & 1985 & & & 1986 & 1985 & 1986 & 1984 & 1987 & & 1986 \\
\hline CABAZITAXEL & 2011 & 2012 & 2011 & 2012 & 2011 & & 2014 & & 2011 & & & 2011 & 2011 & 2011 & 2011 & & 2013 & 2012 \\
\hline CAPECIT & 2003 & 1999 & 2000 & 2001 & 1999 & 1998 & 1999 & 2000 & 2001 & 2001 & 2011 & 2001 & 2001 & 1998 & 2001 & 1999 & 2000 & 2001 \\
\hline CARBOPLATIN & 1989 & 1987 & 1988 & 1994 & 1990 & 1986 & 2001 & 1998 & 1990 & 1998 & 2004 & 1992 & 1988 & 2003 & 1988 & 1987 & 1992 & 2012 \\
\hline CERITINIB & & & 2015 & & & 2015 & & & 2015 & & & & 2015 & 2015 & 2015 & & & \\
\hline CETUXIMAB & 2006 & 2005 & 2004 & 2006 & 2007 & 2008 & 2005 & 2009 & 2004 & 2005 & 2012 & 2005 & 2004 & 2004 & 2004 & 2006 & 2007 & 2004 \\
\hline CLADRIBINE & 1998 & 1994 & 2004 & 2011 & & 1993 & 2009 & 1999 & 1994 & & & 2008 & 1995 & 2005 & 2004 & 1999 & & 1996 \\
\hline CLOFARABINE & 2011 & 2006 & 2007 & 2008 & & & & & & 2012 & & 2007 & 2008 & 2006 & 2006 & & & 2013 \\
\hline \multicolumn{19}{|l|}{ COBIMETINIB } \\
\hline CRIZOTINIB & 2013 & 2014 & 2012 & 2013 & & & 2014 & & 2012 & & & 2013 & 2012 & 2012 & 2012 & & & 2014 \\
\hline DABRAFENIB & & & 2013 & & & 013 & & & 2013 & & & 2014 & 2013 & 2013 & 2013 & & & 2014 \\
\hline \multicolumn{19}{|l|}{ DARATUMUMAB } \\
\hline DASATINIB & 2008 & 2007 & 2007 & 2007 & 2008 & 2007 & 2007 & 2007 & 2006 & 2013 & 2012 & 2007 & 2006 & 2006 & 2006 & 2007 & 2007 & \\
\hline DECITABINE & 2007 & & 2012 & 2013 & 2009 & & & & 2013 & & & 2014 & 2013 & 2014 & 2012 & & 2008 & 2013 \\
\hline DEGARELIX & 2010 & 2010 & 2009 & 2010 & 2012 & & 2014 & & 2009 & & 2013 & 2015 & 2009 & 2010 & 2009 & 2009 & & 2009 \\
\hline \multicolumn{19}{|l|}{ DENILEUKIN DIFTITOX } \\
\hline DENOSUMAB & 011 & 2010 & 2010 & 2010 & 2012 & 2010 & 2011 & & 2010 & & 2013 & 2011 & 2010 & 2012 & 2010 & 2014 & & 2010 \\
\hline \multicolumn{19}{|l|}{ DINUTUXIMAB } \\
\hline DOCETAXEL & 1996 & 1996 & 1996 & 1997 & 1995 & 1995 & 2004 & 2000 & 1996 & 1999 & 2011 & 2010 & 1996 & 2010 & 1996 & 1996 & 1997 & 1996 \\
\hline ENZALUTAMIDE & & 2014 & 2013 & 2014 & & 2013 & 2014 & & 2013 & & & 2014 & 2013 & 2014 & 2013 & & & 2014 \\
\hline EPIRUBICIN & 1984 & 1986 & 1986 & 1986 & 1985 & 1985 & 1985 & 1998 & 1985 & 2001 & 1989 & 1987 & 1986 & 1986 & 1984 & 1985 & 2003 & 1985 \\
\hline ERIBULIN & & 2014 & 2011 & 2013 & 2014 & & & & 2011 & & & 2013 & 2011 & 2012 & 2011 & & & 2012 \\
\hline ERLOTINIB & 2007 & 2006 & 2005 & 2006 & 2006 & 2005 & 2007 & 2006 & 2005 & 2006 & & 2006 & 2005 & 2005 & 2005 & 2006 & 2007 & 2005 \\
\hline EVEROLIMU & 2005 & 2005 & 2004 & 2005 & 2006 & & 2006 & 2004 & 2004 & 2005 & 2011 & 2005 & 2004 & 2005 & 2004 & 2004 & 2009 & 2009 \\
\hline EXEMESTANE & 2000 & 2001 & 2000 & 2000 & 2000 & 2000 & 2006 & 2003 & 2000 & 2001 & 2005 & 2000 & 2000 & 2000 & 2000 & 2001 & 2004 & 2000 \\
\hline FLUDARABINE & 2003 & 1997 & 2015 & 2010 & 2013 & 2013 & & 2004 & 1995 & 2012 & 2012 & 2008 & 2009 & 2008 & 1997 & 1997 & & 2015 \\
\hline FLUTAMIDE & 1986 & 1991 & 1987 & 1986 & 1986 & 1985 & 1983 & 1986 & 1985 & 1988 & 2006 & 1987 & 1993 & 1987 & 1984 & 1987 & 1988 & 1986 \\
\hline FORMESTANE & 1998 & & 1994 & & 1996 & 1994 & 1998 & & 1995 & & 1997 & 1995 & 1996 & 1995 & 1994 & 1995 & 1996 & 1993 \\
\hline FOTEMUSTINE & 1994 & 1993 & 1995 & 2005 & & & & & & & & & & 1989 & & 2000 & & \\
\hline FULVESTRANT & 2005 & 2008 & 2004 & 2006 & 2003 & 2006 & 2009 & 2006 & 2004 & & 2014 & 2004 & 2004 & 2004 & 2004 & 2004 & & 2004 \\
\hline GADOBENIC ACID & & 2006 & 1999 & 2001 & & & & & 2000 & & & 2007 & 2000 & 2002 & 1998 & 2001 & 2011 & 2002 \\
\hline GEFITINIB & 2004 & 2003 & 2009 & 2010 & 2011 & 2004 & 2005 & 2012 & 2009 & & 2015 & 2010 & 2009 & 2002 & 2009 & 2010 & 2004 & 2003 \\
\hline GEMCITABIN & 1996 & 1995 & 2009 & 2009 & 1996 & 1997 & 2006 & 1998 & 1997 & 2001 & 2014 & 1995 & 1995 & 1996 & 1996 & 1997 & 1997 & 2012 \\
\hline GOSERELIN & 1992 & 1989 & 1988 & 1988 & 1992 & 1990 & 2001 & 1997 & 1988 & 1999 & 1997 & 1991 & 1988 & 1988 & 1988 & 1991 & 1992 & \\
\hline IBAN & 2006 & 2008 & 1996 & 2005 & 2006 & 2004 & 2006 & 2006 & 1998 & 2004 & 2012 & 2007 & 1997 & 2007 & 1996 & 2000 & 2007 & 2004 \\
\hline IBRUTINIB & & & 2014 & 2015 & & 2014 & & & 2014 & & & & & 2014 & 2014 & & & 2015 \\
\hline IDARUBICIN & 1991 & 2011 & 1991 & 1992 & 2008 & 1991 & 1998 & 1998 & 1990 & 2001 & 2012 & 2014 & 1993 & 1992 & 1991 & 1998 & 1992 & 1990 \\
\hline IDELALISIB & & & 2014 & & & & & & 2014 & & & & 2014 & 2014 & 2014 & & & \\
\hline IMATINIB & 2001 & 2001 & 2001 & 2002 & 2001 & 2001 & 2004 & 2001 & 2001 & 2001 & 2011 & 2002 & 2001 & 2001 & 2001 & 2002 & 2002 & 2002 \\
\hline INTERFERON ALFA-2A & 1990 & 1988 & 1990 & 1989 & 1989 & 1989 & 1995 & 1992 & 1993 & 1992 & 1993 & 1989 & 1989 & 1996 & 1987 & 1990 & 1995 & 1987 \\
\hline INTERFERON ALFA-2B & 1987 & 2014 & 1987 & 1986 & 1989 & 1986 & 1994 & 1989 & 1986 & 1988 & 1990 & 1988 & 1986 & 1996 & 1987 & 1988 & 2005 & 1985 \\
\hline IPILIMUMAB & & 2014 & 2011 & 2012 & 2013 & & 2014 & 2014 & 2011 & & & 2012 & 2011 & 2011 & 2011 & & & 2012 \\
\hline IRINOTECAN & 1997 & 1997 & 2009 & 2009 & 2001 & 1997 & 2004 & 1998 & 1998 & 2001 & 2007 & 1997 & 1997 & 1995 & 1998 & 1998 & 2000 & 1998 \\
\hline LAPA & 2007 & 2007 & 2008 & 2009 & 2008 & 2009 & 2008 & & 2008 & 2009 & 2011 & 2008 & & 2008 & 2008 & 2008 & 2008 & 2009 \\
\hline \begin{tabular}{|l} 
LENALIDOMIDE \\
\end{tabular} & 2011 & & 2007 & 2008 & & & 2011 & 2009 & 2007 & 2009 & & 2008 & 2008 & 2007 & 2007 & 2011 & & 2007 \\
\hline LENVATINIB & & & 2015 & & & & & & 2015 & & & & 2015 & 2015 & 2015 & & & \\
\hline LETRO & 1998 & 1997 & 1997 & 1999 & 1998 & 1997 & 2000 & 1999 & 1997 & 1999 & 1998 & 1997 & 1997 & 1997 & 1997 & 1998 & 2002 & 2000 \\
\hline LEUPRORELIN & 1987 & 1986 & 1994 & 2005 & 1990 & 1985 & 1992 & 1989 & 1992 & 1994 & 2009 & 1986 & 1992 & 1987 & 1984 & 1990 & 1993 & 1991 \\
\hline MILTEFOSINE & 1998 & & & & & & 2000 & & & 2007 & & 1999 & 2007 & 1997 & 1993 & & & \\
\hline MITOXANTRONE & 1987 & 1985 & 2004 & 1986 & 1987 & 1984 & 1989 & 2006 & 1987 & 2001 & 1990 & 1995 & 1989 & 1986 & 1985 & 1987 & & 1984 \\
\hline NELARABINE & & & 2009 & 2008 & & 2008 & & & 2007 & & & 2008 & 2007 & 2008 & 2007 & & & 2007 \\
\hline NILOTINIB & & 2008 & 2008 & 2008 & 2009 & 2008 & 2012 & 2009 & 2008 & & 2012 & 2008 & 2008 & 2008 & 2008 & 2008 & 2007 & 2008 \\
\hline
\end{tabular}


Appendix Table 3

Drug launch years

\begin{tabular}{|c|c|c|c|c|c|c|c|c|c|c|c|c|c|c|c|c|c|c|}
\hline & 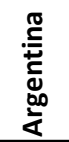 & 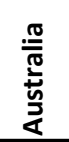 & 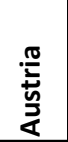 & $\frac{\varepsilon}{\frac{E}{5}}$ & $\begin{array}{l}\overline{\bar{N}} \\
\overline{\mathbb{N}} \\
\bar{\infty}\end{array}$ & $\begin{array}{l}\frac{\pi}{0} \\
\frac{\pi}{\pi} \\
\frac{\pi}{\pi} \\
0\end{array}$ & $\frac{0}{\frac{U}{c}}$ & $\begin{array}{l}\text { 응 } \\
\text { 응 } \\
\end{array}$ & 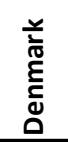 & 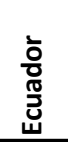 & 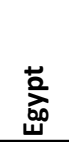 & $\begin{array}{l}\frac{5}{\pi} \\
\text { nั }\end{array}$ & 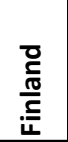 & 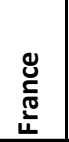 & 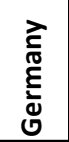 & 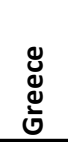 & 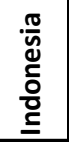 & $\begin{array}{l}\overline{0} \\
\frac{C}{\pi} \\
\underline{\underline{0}}\end{array}$ \\
\hline NILUTAMIDE & 1990 & 1997 & & & 1989 & 1992 & & 1998 & 1998 & & 1994 & & 1993 & 1987 & & 1999 & & \\
\hline NIVOLUMAB & & & 2015 & & & & & & 2015 & & & & 2015 & & 2015 & & & 2015 \\
\hline OBINUTUZUMAB & & 2015 & 2015 & & & 2014 & & & 2014 & & & & 2014 & & 2014 & & & 2015 \\
\hline OCTREOTIDE & 1999 & 2000 & 2010 & 1988 & 2008 & 1999 & 1993 & 1991 & 1988 & 1996 & 2005 & 1993 & 1990 & 1991 & 1991 & 1990 & 1992 & 1988 \\
\hline OFATUMUMAB & & 2015 & 2010 & & & & & & 2010 & & & 2014 & 2010 & 2010 & 2010 & 2011 & & \\
\hline OXALIPLATIN & 1997 & 2007 & 2006 & 2008 & 2001 & 2007 & 1998 & 1998 & 2006 & 1999 & 2004 & 2007 & 2006 & 1996 & 1999 & 2005 & 2001 & 2003 \\
\hline PACLITAXEL & 1993 & 1996 & 1993 & 1994 & 1994 & 1993 & 1998 & 2004 & 1994 & 2003 & 1996 & 2004 & 1994 & 1994 & 1994 & 1994 & 1994 & 2004 \\
\hline PANITUMUMAB & 2011 & 2006 & 2008 & 2008 & 2011 & 2008 & 2012 & & 2008 & 2015 & 2009 & 2008 & 2008 & 2008 & 2008 & & & 2008 \\
\hline PANOBINOSTAT & & & 2015 & & & & & & & & & & 2015 & & & & & \\
\hline PASIREOTIDE & & & 2012 & & & 2013 & & & 2012 & & & & 2012 & 2012 & 2012 & & & \\
\hline PAZOPANIB & 2015 & 2010 & 2010 & 2011 & 2011 & 2010 & 2011 & 2012 & 2010 & 2011 & & 2011 & 2010 & 2013 & 2010 & 2011 & 2011 & 2010 \\
\hline PEGASPARGASE & & & & & & 1998 & & & & & & & & 2003 & 1997 & & & \\
\hline PEMBROLIZUMAB & & 2015 & 2015 & & & & & & & & & & 2015 & 2015 & 2015 & & & \\
\hline PEMETREXED & 2006 & 2004 & 2005 & 2006 & 2005 & 2004 & 2007 & 2007 & 2005 & 2006 & 2007 & 2005 & 2004 & 2004 & 2004 & 2004 & 2011 & 2005 \\
\hline PENTOSTATIN & & & & & & 1993 & & & 2010 & & & & & & 1994 & 2007 & & \\
\hline PERTUZUMAB & & 2013 & 2013 & & & & & & 2013 & 2014 & & 2014 & 2013 & & 2013 & & & \\
\hline PIRARUBICIN & 1996 & & 1991 & & & & & & & & & & & 1990 & & & & \\
\hline PIXANTRONE & & & 2012 & & & & & & & & & & 2012 & & 2012 & & & 2015 \\
\hline PLERIXAFOR & & 2011 & 2009 & 2010 & 2012 & & 2015 & & 2009 & & & 2010 & 2009 & 2010 & 2009 & & & 2013 \\
\hline PONATINIB & & 2015 & 2013 & & & & & & & & & & 2013 & 2013 & 2013 & & & 2015 \\
\hline PORFIMER SODIUM & 2011 & & & & & 1993 & & & & & & & & 1999 & 1999 & & & \\
\hline RALTITREXED & 1998 & 1997 & 1998 & & 2000 & 1996 & & 1999 & & & & & 1997 & & & & & 1996 \\
\hline RAMUCIRUMAB & & 2015 & 2015 & & & & & & 2015 & & & & 2015 & 2014 & & & & 2015 \\
\hline REGORAFENIB & & 2014 & 2013 & 2015 & & 2013 & & & 2013 & & & & & 2015 & 2013 & & & \\
\hline RITUXIMAB & 2005 & 1998 & 1998 & 2000 & & 2000 & 2001 & 2000 & 1998 & 2002 & 2011 & 1999 & 1998 & & 1998 & 1999 & 2004 & 1998 \\
\hline \multicolumn{19}{|l|}{ ROMIDEPSIN } \\
\hline SORAFENIB & & 2006 & 2006 & 2007 & 2006 & 2006 & 2006 & 2007 & 2006 & 2007 & 2011 & 2007 & 2006 & 2006 & 2006 & 2006 & 2007 & 2006 \\
\hline STREPTOZOCIN & & 2003 & 1987 & & & 1985 & & & & & & & & & & & & \\
\hline SUNITINIB & 2009 & 2006 & 2006 & 2007 & 2006 & 2006 & 2007 & 2007 & 2006 & 2007 & 2011 & 2007 & 2006 & 2006 & 2006 & 2006 & 2008 & 2006 \\
\hline TEMOZOLOMIDE & 1999 & 2000 & 1999 & 2001 & 2000 & 1999 & 2000 & 2002 & 1999 & 2003 & 2011 & 1999 & 1999 & 1998 & 1999 & 1999 & 2002 & 1999 \\
\hline TEMSIROLIMUS & 2011 & 2009 & 2008 & 2008 & 2010 & 2008 & 2008 & & 2008 & & & 2008 & 2008 & 2008 & 2007 & 2008 & & 2008 \\
\hline TOPOTECAN & 1997 & 1997 & 1997 & 2011 & 1997 & 1997 & 2007 & 2007 & 1997 & 2000 & 2012 & 2008 & 1997 & 1997 & 1997 & 1998 & & 1997 \\
\hline TOREMIFENE & 1997 & 1997 & 1997 & 1999 & 1997 & & & 1998 & 1997 & & & 1997 & 1989 & 2000 & 1996 & 1997 & & 1996 \\
\hline TRABECTEDIN & & & 2007 & 2009 & & 2010 & 2014 & & 2007 & 2012 & 2013 & 2007 & 2007 & 2008 & 2007 & & & 2008 \\
\hline TRAMETINIB & & 2014 & 2015 & & & 2013 & & & 2015 & & & & 2015 & & & & & \\
\hline TRASTUZUMAB & 2005 & 2015 & 2000 & 2001 & 1999 & 1999 & 2007 & 2001 & & 2002 & 2011 & & 2000 & 1999 & 2000 & 2000 & 2003 & 2000 \\
\hline TRASTUZUMAB EMTANSINE & & & & 2014 & 2014 & 2013 & 2014 & 2014 & & 2014 & & & & 2014 & & & & 2015 \\
\hline VANDETANIB & 2014 & & 2012 & 2013 & & & & & 2012 & & & & 2012 & & 2012 & & & 2014 \\
\hline VEMURAFENIB & & 2012 & 2012 & & 2012 & & 2015 & & 2012 & & & 2013 & 2012 & 2013 & 2012 & & & 2013 \\
\hline VINORELBINE & 1991 & 2004 & 1994 & 1999 & 1995 & 1994 & 2002 & 2005 & 1998 & 2005 & 2011 & 1993 & 1996 & 1989 & 1996 & 1997 & 2004 & 2007 \\
\hline ZORUBICIN & & & & & & & & & & & & & & & 1987 & & & \\
\hline
\end{tabular}


Appendix Table 3

Drug launch years

\begin{tabular}{|c|c|c|c|c|c|c|c|c|c|c|c|c|c|c|c|c|c|c|}
\hline & $\frac{\vec{D}}{ \pm}$ & 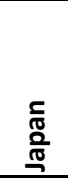 & 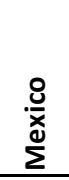 & 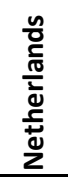 & $\begin{array}{l}\frac{c}{\pi} \\
\frac{5}{5} \\
\frac{5}{0} \\
\end{array}$ & $\begin{array}{l}\overrightarrow{2} \\
\stackrel{0}{0} \\
\end{array}$ & 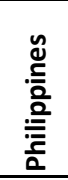 & 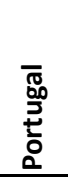 & 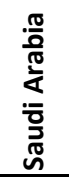 & 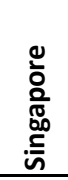 & 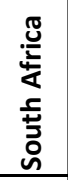 & 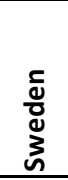 & 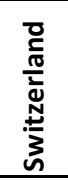 & 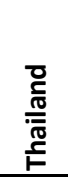 & 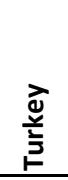 & 兰 & ฝૂ & 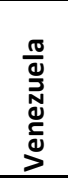 \\
\hline AFATINIB & & 2014 & & & & & 2015 & & & 2013 & & & 2014 & & & 2013 & 2013 & \\
\hline AFLIBERCEPT & 2013 & 2012 & 2014 & 2012 & & & 2014 & 2013 & & 2013 & & 2012 & 2012 & 2014 & 2014 & 2012 & 2011 & \\
\hline ALEMTUZUMAB & 2002 & 2015 & & 2001 & & & & & & 2004 & 2006 & 2001 & 2002 & 2007 & 2007 & 2001 & 2001 & \\
\hline AMIFOSTINE & 1998 & & 1997 & 1996 & 2002 & 2002 & 1996 & & & 1998 & 1996 & 1998 & 1997 & 1999 & 1998 & 1995 & 1996 & 2001 \\
\hline AMSACRINE & & & & 1982 & & & & 2013 & & 1992 & & 1983 & 1993 & & & 1984 & & \\
\hline ANASTROZOLE & 1996 & 2001 & 1998 & 1997 & 2000 & 2004 & 1999 & 1998 & 2001 & 1997 & 1996 & 1996 & 1996 & 1998 & 1998 & 1995 & 1996 & 1999 \\
\hline ARSENIC TRIOXIDE & 2004 & 2004 & & & & & & & & & & & & & & 2006 & 2000 & \\
\hline AZACITIDINE & 2010 & 2011 & 2012 & 2008 & & & 2011 & & & 2010 & 2010 & 2009 & 2006 & 2007 & 2007 & & 2004 & \\
\hline BEVACIZUMAB & 2005 & 2007 & 2005 & 2005 & 2005 & & 2006 & & & 2005 & 2006 & 2005 & 2004 & 2005 & 2006 & 2005 & 2004 & \\
\hline BEXAROTENE & 2004 & & & 2003 & & & & & & & & 2001 & & & 2015 & 2002 & 2000 & \\
\hline BICALUTAMIDE & 1996 & 1999 & 1997 & 1995 & 2003 & 2006 & 2000 & 1999 & & 1998 & 1996 & 1996 & 1996 & \begin{tabular}{|l|}
1998 \\
\end{tabular} & 1996 & 1995 & 1995 & 1997 \\
\hline BLINATUMOMAE & & & & & & & & & & & & & & & & & 2014 & \\
\hline BORTEZOMIB & 2005 & 2006 & 2006 & 2004 & & 2013 & 2006 & & 2008 & 2005 & 2006 & 2004 & 2005 & 2006 & 2005 & 2004 & 2003 & \\
\hline BOSUTINIB & & 2014 & & & & & & & & & & 2013 & 2014 & & & 2013 & 2012 & \\
\hline BRENTUXIMAB VEDOTIN & 2014 & 2014 & 2014 & & & & & 2012 & & 2014 & & 2012 & 2013 & & & 2012 & 2011 & \\
\hline BUSERELIN & 1985 & 1988 & 2000 & 1985 & & & 1987 & 1988 & 1992 & 1986 & 1988 & 1988 & 1995 & 1992 & 1988 & 1986 & & \\
\hline CABAZITAXEL & & 2014 & 2012 & 2011 & & 2012 & 2012 & & & 2012 & 2012 & 2011 & 2011 & 2012 & 2013 & 2011 & 2010 & \\
\hline CAPECITABINE & 2001 & 2003 & 2000 & 2001 & 2002 & 2012 & 1999 & 2013 & 2006 & 1999 & 2000 & 2001 & 1998 & 1998 & 2002 & 2001 & 1998 & 1999 \\
\hline CARBOPLATIN & 1989 & 1990 & 1992 & 1986 & 1991 & 1998 & 1988 & 2011 & 1996 & 1986 & 2010 & 1987 & 1986 & 1999 & 1994 & 1986 & 1989 & 2002 \\
\hline CERITINIB & & & & 2015 & & & & 2015 & & & & 2015 & & & & 2015 & 2014 & \\
\hline CETUXIMAB & 2005 & 2008 & 2004 & 2004 & 2009 & & 2005 & & & 2005 & 2008 & 2004 & 2003 & 2007 & 2014 & 2004 & 2004 & \\
\hline CLADRIBINE & 1999 & 2002 & & 1996 & & & 2004 & 2012 & & & 2000 & 1994 & 1999 & 1996 & 2014 & 1995 & 1993 & \\
\hline CLOFARABINE & 2008 & 2013 & 2009 & & & & & & & 2008 & & & & 2013 & 2013 & 2006 & 2005 & \\
\hline COBIMETINIB & & & & & & & & & & & & & 2015 & & & & 2015 & \\
\hline CRIZOTINIB & & 2012 & 2012 & & & & 2015 & & 2013 & 2012 & & 2012 & 2012 & 2013 & 2015 & 2012 & 2011 & \\
\hline DABRAFENIB & 2014 & & & 2013 & & & & & & & & 2013 & & & 2015 & & 2013 & \\
\hline DARATUMUMAB & & & & & & & & & & & & & & & & & 2015 & \\
\hline DASATINIB & 2007 & 2009 & 2007 & 2006 & & 2014 & 2007 & & 2008 & 2007 & 2009 & 2006 & 2007 & 2008 & 2008 & 2006 & 2006 & \\
\hline DECITABINE & 2014 & & & 2012 & & & 2009 & & & 2013 & & & 2012 & 2009 & 2010 & 2013 & 2006 & \\
\hline DEGARELIX & & 2012 & 2010 & 2009 & & & & & 2012 & 2014 & 2014 & 2010 & 2010 & 2014 & & 2009 & 2009 & \\
\hline DENILEUKIN DIFTITOX & & & & & & & & & & & & & & & & & 1999 & \\
\hline DENOSUMAB & 2011 & 2012 & 2012 & 2011 & & 2011 & 2012 & 2012 & 2013 & 2012 & 2014 & 2010 & 2010 & 2013 & 2013 & 2010 & 2010 & \\
\hline DINUTUXIMAB & & & & & & & & & & & & & & & & & 2015 & \\
\hline DOCETAXEL & 1996 & 1997 & 1995 & 1996 & 2005 & 1997 & 1997 & 2011 & 1997 & 1997 & 1995 & 2010 & 1997 & 1997 & 1997 & 1996 & 1996 & 1996 \\
\hline ENZALUTAMIDE & 2014 & 2014 & & 2013 & & & & & & & & & 2013 & & & 2013 & 2012 & \\
\hline EPIRUBICIN & 1984 & 1989 & 1987 & 1986 & 1988 & 2006 & 1986 & 2011 & 1989 & 1985 & 2009 & 1987 & 1984 & 1986 & 2003 & 1985 & 1999 & \\
\hline ERIBULIN & 2012 & 2011 & & 2011 & & & 2013 & & & 2011 & & 2011 & 2011 & 2013 & & 2011 & 2010 & \\
\hline ERLOTINIB & 2006 & 2007 & 2006 & 2005 & 2006 & & 2006 & & & 2006 & 2009 & 2005 & 2005 & 2005 & 2009 & 2005 & 2004 & \\
\hline EVEROLIMUS & 2005 & 2007 & 2006 & 2004 & 2007 & 2014 & 2006 & & 2008 & 2006 & 2005 & 2003 & 2005 & 2005 & 2005 & 2009 & 2009 & \\
\hline EXEMESTANE & 2000 & 2002 & 2004 & 2000 & 2011 & 2002 & 2003 & 2000 & 2011 & 2001 & 2002 & 1999 & 1999 & 2001 & 2005 & 2000 & 2000 & 2010 \\
\hline FLUDARABINE & 1995 & 2010 & & 1994 & & 2012 & & & 2012 & & 2011 & 2014 & 2008 & & 1994 & 2010 & 1992 & \\
\hline FLUTAMIDE & 1986 & 1994 & 1987 & 1989 & 1995 & 1995 & 1986 & 1984 & 1990 & 2005 & 1985 & 1993 & 1985 & 1989 & 1990 & 1990 & 1989 & 1992 \\
\hline FORMESTANE & 1995 & & & 1994 & 1999 & & 1997 & & & & & & 1995 & 1996 & 1996 & 1993 & & \\
\hline FOTEMUSTINE & 2001 & & & & & & & & & & & & & & 1996 & & & \\
\hline FULVESTRANT & 2005 & 2011 & 2009 & 2004 & & 2009 & 2007 & & & 2006 & 2007 & 2004 & 2004 & 2009 & 2006 & 2004 & 2002 & \\
\hline GADOBENIC ACID & 1999 & & & 2000 & & & 2013 & & & & & 1998 & & 2009 & 2004 & 1999 & 2005 & \\
\hline GEFITINIB & 2010 & 2002 & 2004 & 2009 & & & 2003 & & & 2003 & & & 2004 & 2004 & & 2009 & 2003 & \\
\hline GEMCITABINE & 1996 & 1999 & 1997 & 1995 & 1999 & 1997 & 1997 & 2013 & 2001 & 2012 & 1995 & 1995 & 1997 & 1997 & 1997 & 1995 & 1996 & 1995 \\
\hline GOSERELIN & 1988 & 1991 & 1991 & 1988 & & 2006 & 1994 & 1988 & 1994 & 1992 & & 1988 & 1991 & 1994 & 1993 & 1987 & 1990 & 1998 \\
\hline IBANDRONIC & 2005 & 2013 & 2006 & 2004 & 2006 & 2006 & 2004 & 2006 & 2007 & 2000 & 2002 & 2008 & 1999 & 1998 & 2007 & 2002 & 2005 & 2006 \\
\hline IBRUTINIB & & & & 2014 & & & & 2015 & & & & 2015 & 2015 & & & & 2013 & \\
\hline IDARUBICIN & 1990 & 1995 & 1992 & 1991 & 2001 & 2006 & 1993 & 2013 & 1991 & 1993 & & 1993 & 1992 & 1994 & 1995 & 1990 & 1990 & \\
\hline IDELALISIB & 2015 & & & & & & & 2015 & & & & 2014 & 2015 & & & & 2014 & \\
\hline IMATINIB & 2002 & 2001 & 2001 & 2001 & 2002 & 2006 & 2002 & & 2004 & 2001 & 2002 & 2001 & 2001 & 2001 & 2002 & 2001 & 2001 & 1990 \\
\hline INTERFERON ALFA-2A & 1987 & 1988 & 1993 & 1986 & 1992 & & 1988 & 1988 & 1990 & & 1988 & 1989 & 1986 & 1988 & 1991 & 1986 & 1986 & 1993 \\
\hline INTERFERC & 1987 & 1988 & 1987 & 1986 & 1995 & 1998 & 1987 & 1989 & 1988 & & 1986 & 1986 & 1986 & 1988 & 1991 & 1986 & 1986 & 2001 \\
\hline IPILIMUMAB & 2013 & 2015 & 2012 & & & 2014 & & 2012 & & & 2015 & 2011 & 2011 & & & 2011 & 2011 & \\
\hline IRINOTECAN & 1997 & 1994 & 1998 & 1998 & 2008 & 2002 & 1997 & 2012 & 2003 & 1996 & 2009 & 1998 & 1998 & 1998 & 1998 & 1997 & 1996 & 2004 \\
\hline LAPATINIB & 2009 & 2009 & 2009 & & 2010 & 2009 & 2007 & 2008 & 2008 & 2007 & 2010 & 2008 & 2007 & 2008 & 2008 & 2008 & 2007 & \\
\hline LENALIDOMIDE & 2008 & 2010 & 2008 & 2007 & & & 2010 & & & & 2014 & 2008 & & 2011 & 2010 & 2007 & 2006 & \\
\hline LENVATINIB & & 2015 & & & & & & & & & & 2015 & 2015 & & & & 2015 & \\
\hline LETROZOLE & 1997 & 2006 & 2000 & 1998 & 1999 & 2009 & 1998 & 2002 & 2002 & 2014 & 1997 & 1996 & 1997 & 1998 & 1999 & 1996 & 1997 & 1997 \\
\hline LEUPRORELIN & 1989 & 1992 & 1989 & 1989 & 2002 & 1994 & 1992 & 1987 & 1997 & & 2012 & 1987 & 1993 & 1994 & 1995 & 1991 & 1985 & 1992 \\
\hline MILTEFOSINE & 2003 & & & & & & 1999 & & & 2003 & & & & & & & & \\
\hline MITOXANTRONE & 1987 & 1987 & 1987 & 1986 & 1999 & 2001 & 1986 & & 2011 & 1986 & 2007 & 1988 & 1985 & \begin{tabular}{|l|}
1998 \\
\end{tabular} & 1999 & 1984 & 1988 & 2004 \\
\hline NELARABINE & 2008 & 2007 & & & & & & & & & & 2007 & 2007 & & & 2007 & 2006 & \\
\hline NILOTINIB & 2008 & 2009 & 2007 & 2007 & 2009 & 2012 & 2008 & & 2009 & 2008 & 2008 & 2008 & 2007 & 2008 & 2009 & 2008 & 2007 & \\
\hline
\end{tabular}


Appendix Table 3

\begin{tabular}{|c|c|c|c|c|c|c|c|c|c|c|c|c|c|c|c|c|c|c|}
\hline & $\stackrel{2}{\mathbb{\pi}}$ & $\begin{array}{l}\frac{5}{\pi} \\
\frac{0}{\pi} \\
\frac{0}{\pi}\end{array}$ & 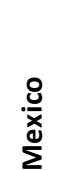 & 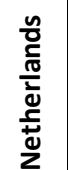 & 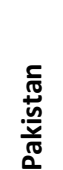 & হై & 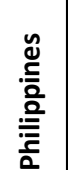 & 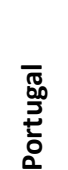 & $\begin{array}{l}\frac{\pi}{0} \\
\frac{0}{0} \\
\frac{10}{4} \\
\frac{\overline{0}}{3} \\
\frac{\pi}{n}\end{array}$ & 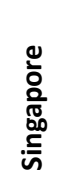 & 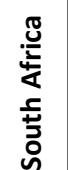 & 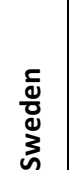 & 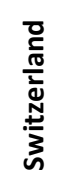 & 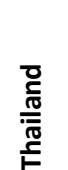 & 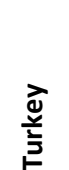 & 弚 & હ & 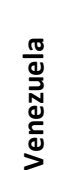 \\
\hline NILUTAMIDE & & & 2000 & 1990 & & 1994 & & 1989 & & & & 1990 & & & & & 1996 & \\
\hline NIVOLUMAB & & 2014 & & & & & & 2015 & & & & 2015 & & & & & 2014 & \\
\hline OBINUTUZUMAB & & & 2014 & 2014 & & & & & & & & 2014 & & & & 2014 & 2013 & \\
\hline OCTREOTIDE & 1990 & 1989 & 1990 & 1989 & 1994 & 1998 & 2010 & 1991 & 1990 & 1990 & 1990 & 1989 & 1988 & 1992 & 1992 & 1989 & 1989 & \\
\hline OFATUMUMAB & 2011 & 2013 & & 2010 & & & & & & & & 2010 & 2011 & & & 2010 & 2009 & \\
\hline OXALIPLATIN & 2000 & 2005 & 2002 & 2007 & 2005 & 2002 & 1999 & 2015 & 2004 & 1999 & 2006 & 1999 & 1999 & 1999 & 2004 & 1999 & 2002 & \\
\hline PACLITAXEL & 1995 & 1997 & 1995 & 1993 & 2000 & 2002 & 1994 & 2015 & 1996 & 1994 & 1999 & 1993 & 1994 & 1994 & 1996 & 1993 & 1992 & 1998 \\
\hline PANITUMUMAB & 2009 & 2010 & 2011 & & & & 2014 & & & 2014 & & 2007 & 2008 & & 2013 & 2008 & 2006 & \\
\hline PANOBINOSTAT & & 2015 & & 2015 & & & & & & & & & & & & & 2015 & \\
\hline PASIREOTIDE & & & 2013 & & & & & & & & & 2012 & 2013 & 2015 & 2015 & 2012 & 2013 & \\
\hline PAZOPANIB & & 2012 & 2012 & 2010 & 2011 & & 2011 & & & 2011 & & 2010 & 2010 & 2012 & 2011 & 2010 & 2009 & \\
\hline PEGASPARGASE & & & & & & & & & & & & & & & & & 1994 & \\
\hline PEMBROLIZUMAB & & & & & & & & 2015 & & & & 2015 & 2015 & & & 2015 & 2014 & \\
\hline PEMETREXED & 2005 & 2007 & 2005 & 2004 & 2007 & & 2006 & & 2008 & 2004 & 2006 & 2004 & 2005 & 2004 & 2004 & 2004 & 2004 & \\
\hline PENTOSTATIN & 1996 & 1996 & & 1993 & & & & & & & & & & & & 1993 & 1992 & \\
\hline PERTUZUMAB & & & & 2013 & & & & & & & & 2013 & 2012 & 2014 & & 2013 & 2012 & \\
\hline PIRARUBICIN & & 1988 & & & & & & & & & & & & & & & & \\
\hline PIXANTRONE & 2015 & & & & & & & & & & & 2012 & & & & 2013 & & \\
\hline PLERIXAFOR & 2012 & & 2009 & & & & & & & 2011 & 2014 & & 2015 & 2013 & & 2009 & 2009 & \\
\hline PONATINIB & 2015 & & & & & & & & & & & 2013 & & & & & 2013 & \\
\hline PORFIMER SODIUM & & 1996 & & 1999 & & & & & & & & & & & & 2001 & 1996 & \\
\hline RALTITREXED & 1997 & & 2003 & 1997 & & & 2000 & & & 2000 & 2000 & & 1999 & & 2002 & 1996 & & 1999 \\
\hline RAMUCIRUMAB & & 2015 & & & & & & & & & & 2015 & & & & 2015 & 2014 & \\
\hline REGORAFENIB & & 2013 & & 2013 & & 2014 & 2014 & 2013 & & & 2014 & 2013 & 2013 & 2014 & 2015 & & 2012 & \\
\hline RITUXIMAB & 1999 & 2001 & 1999 & 1998 & 2004 & 2006 & 1998 & & 2008 & 1998 & 1999 & 1998 & 1997 & 1999 & 2002 & 1998 & 1997 & 1997 \\
\hline ROMIDEPSIN & & & & & & & & & & & & & & & & & 2010 & \\
\hline SORAFENIB & 2006 & 2008 & & 2006 & 2009 & 2014 & 2007 & & 2012 & 2007 & 2007 & 2006 & 2006 & 2007 & 2008 & 2006 & 2005 & \\
\hline STREPTOZOCIN & & 2015 & & 1998 & & & & & & & & & 2008 & & & & 1982 & \\
\hline SUNITINIB & 2006 & 2008 & 2006 & 2006 & 2009 & & 2006 & & 2011 & 2007 & 2008 & 2006 & 2006 & 2007 & 2008 & 2006 & 2006 & \\
\hline TEMOZOLOMIDE & 2000 & 2006 & 1999 & 1999 & & 2002 & 2002 & & & 1999 & 1999 & 1999 & 1999 & 2001 & 2003 & 1999 & 1999 & \\
\hline TEMSIROLIMUS & 2008 & 2010 & 2011 & & & & 2010 & & 2012 & 2011 & 2010 & 2008 & 2009 & 2012 & 2009 & 2008 & 2007 & \\
\hline TOPOTECAN & 1997 & 2001 & 2008 & 1996 & 2008 & 2006 & 2007 & 2013 & 2011 & & 2000 & 1997 & 1997 & 1998 & 2000 & 1997 & 1996 & 2001 \\
\hline TOREMIFENE & 1997 & 1995 & 1999 & & & 1997 & & & & & 1998 & 1994 & 1997 & & 2006 & 1996 & 1997 & 2001 \\
\hline TRABECTEDIN & 2009 & & 2010 & & & & 2010 & & & 2009 & 2013 & 2007 & 2011 & 2010 & 2013 & 2007 & 2015 & \\
\hline TRAMETINIB & & & & 2014 & & & & & & & & & & & & & 2013 & \\
\hline TRASTUZUMAB & 2001 & 2001 & 2000 & 2013 & 2004 & & 2000 & & 2008 & 1999 & 2002 & 2000 & 1999 & 2001 & 2003 & 2000 & 1998 & 1999 \\
\hline TRASTUZUMAB EMTANSINE & 2014 & & 2014 & & & & & 2014 & & & & & 2013 & & & & 2013 & \\
\hline VANDETANIB & & & 2014 & 2012 & & & & 2015 & & & & 2012 & 2012 & & & 2012 & 2011 & \\
\hline VEMURAFENIB & & 2015 & 2012 & 2012 & & & & 2013 & & 2012 & 2013 & 2012 & 2011 & 2014 & 2014 & 2012 & 2011 & \\
\hline VINORELBINE & 1992 & 1999 & 1998 & 2002 & 1995 & 1993 & 1998 & & & 1992 & 1999 & 1996 & 2007 & 1998 & 1995 & 1997 & 1995 & \\
\hline ZORUBICIN & & & & & & & & & & & & & & & & & & \\
\hline
\end{tabular}


Appendix Table 4

Complete estimates of In(DALYS_2015) model

\begin{tabular}{|c|c|c|c|c|c|c|}
\hline Parameter & Estimate & Standard & $95 \%$ Con & ce Limits & $\bar{Z}$ & $\operatorname{Pr}>|Z|$ \\
\hline$\beta_{0-4}$ & 0.000 & 0.013 & -0.026 & 0.025 & -0.03 & 0.9772 \\
\hline$\beta_{5-9}$ & -0.058 & 0.012 & -0.082 & -0.034 & -4.81 & $<.0001$ \\
\hline$\beta_{10-14}$ & -0.026 & 0.011 & -0.047 & -0.004 & -2.35 & 0.0187 \\
\hline$\beta_{15-33}$ & -0.027 & 0.009 & -0.045 & -0.009 & -2.96 & 0.0031 \\
\hline$\gamma$ & 0.849 & 0.032 & 0.786 & 0.912 & 26.27 & $<.0001$ \\
\hline Argentina (ARG) & -0.011 & 0.060 & -0.129 & 0.107 & -0.18 & 0.8588 \\
\hline Australia (AUS) & -0.478 & 0.075 & -0.625 & -0.331 & -6.37 & $<.0001$ \\
\hline \begin{tabular}{|l|} 
Austria (AUT) \\
\end{tabular} & -0.387 & 0.109 & -0.600 & -0.173 & -3.54 & 0.0004 \\
\hline \begin{tabular}{|l|} 
Belgium (BEL) \\
\end{tabular} & -0.372 & 0.139 & -0.645 & -0.099 & -2.67 & 0.0076 \\
\hline Brazil (BRA) & 0.207 & 0.067 & 0.076 & 0.338 & 3.10 & 0.0019 \\
\hline Canada (CAN) & -0.345 & 0.081 & -0.504 & -0.185 & -4.23 & $<.0001$ \\
\hline Chile $(\mathrm{CHL})$ & -0.126 & 0.077 & -0.277 & 0.026 & -1.63 & 0.104 \\
\hline Colombia (COL) & 0.257 & 0.076 & 0.109 & 0.406 & 3.40 & 0.0007 \\
\hline \begin{tabular}{|l|} 
Denmark (DNK) \\
\end{tabular} & -0.498 & 0.108 & -0.710 & -0.287 & -4.61 & $<.0001$ \\
\hline Ecuador (ECU) & -0.107 & 0.119 & -0.340 & 0.127 & -0.89 & 0.3708 \\
\hline Egypt (EGY) & 0.137 & 0.087 & -0.035 & 0.308 & 1.57 & 0.1175 \\
\hline Finland (FIN) & -0.601 & 0.118 & -0.832 & -0.369 & -5.08 & $<.0001$ \\
\hline France (FRA) & -0.079 & 0.074 & -0.224 & 0.065 & -1.08 & 0.2823 \\
\hline Germany (DEU) & -0.099 & 0.080 & -0.255 & 0.057 & -1.24 & 0.2145 \\
\hline Greece (GRC) & -0.275 & 0.074 & -0.420 & -0.130 & -3.71 & 0.0002 \\
\hline Indonesia (IDN) & 0.393 & 0.067 & 0.262 & 0.524 & 5.88 & $<.0001$ \\
\hline Ireland (IRL) & -0.664 & 0.109 & -0.877 & -0.450 & -6.08 & $<.0001$ \\
\hline \begin{tabular}{|l|} 
Italy (ITA) \\
\end{tabular} & -0.202 & 0.074 & -0.346 & -0.058 & -2.74 & 0.0061 \\
\hline Japan (JPN) & -0.148 & 0.090 & -0.325 & 0.028 & -1.65 & 0.0993 \\
\hline \begin{tabular}{|l} 
Mexico (MEX) \\
\end{tabular} & 0.085 & 0.063 & -0.039 & 0.208 & 1.34 & 0.181 \\
\hline Netherlands (NLD) & -0.304 & 0.114 & -0.528 & -0.080 & -2.66 & 0.0077 \\
\hline Pakistan (PAK) & 0.608 & 0.062 & 0.486 & 0.730 & 9.77 & $<.0001$ \\
\hline Peru (PER) & -0.137 & 0.054 & -0.243 & -0.031 & -2.54 & 0.0111 \\
\hline Philippines (PHL) & 0.440 & 0.069 & 0.305 & 0.575 & 6.38 & $<.0001$ \\
\hline \begin{tabular}{|l|} 
Portugal (PRT) \\
\end{tabular} & -0.467 & 0.064 & -0.593 & -0.342 & -7.31 & $<.0001$ \\
\hline Saudi Arabia (SAU) & -0.024 & 0.090 & -0.201 & 0.153 & -0.26 & 0.7918 \\
\hline Singapore (SGP) & -0.506 & 0.124 & -0.748 & -0.263 & -4.09 & $<.0001$ \\
\hline South Africa (ZAF) & 0.381 & 0.091 & 0.202 & 0.559 & 4.17 & $<.0001$ \\
\hline Spain (ESP) & -0.165 & 0.084 & -0.330 & 0.001 & -1.95 & 0.0509 \\
\hline Sweden (SWE) & -0.443 & 0.112 & -0.663 & -0.223 & -3.95 & $<.0001$ \\
\hline Switzerland (CHE) & -0.594 & 0.113 & -0.815 & -0.373 & -5.27 & $<.0001$ \\
\hline Thailand (THA) & 0.292 & 0.069 & 0.157 & 0.427 & 4.24 & $<.0001$ \\
\hline Turkey (TUR) & 0.344 & 0.055 & 0.236 & 0.451 & 6.26 & $<.0001$ \\
\hline United Kingdom (GBR) & -0.140 & 0.076 & -0.289 & 0.009 & -1.84 & 0.0657 \\
\hline United States of America (USA) & 0.015 & 0.093 & -0.167 & 0.196 & 0.16 & 0.8745 \\
\hline Venezuela (Bolivarian Republic of) (VEN) & 0.000 & 0.000 & 0.000 & 0.000 & & \\
\hline C15 Oesophagus cancer & -0.547 & 0.099 & -0.741 & -0.354 & -5.56 & $<.0001$ \\
\hline C16 Stomach cancer & -0.594 & 0.084 & -0.759 & -0.430 & -7.08 & $<.0001$ \\
\hline C18-C21 Colon and rectum cancers & -0.729 & 0.088 & -0.902 & -0.556 & -8.27 & $<.0001$ \\
\hline C22 Liver cancer & -0.380 & 0.097 & -0.569 & -0.191 & -3.93 & $<.0001$ \\
\hline C25 Pancreas cancer & -0.212 & 0.066 & -0.341 & -0.083 & -3.22 & 0.0013 \\
\hline C33-C34 Trachea, bronchus, lung cancers & -0.062 & 0.073 & -0.205 & 0.081 & -0.85 & 0.3949 \\
\hline C43 Malignant skin melanoma & -1.682 & 0.098 & -1.873 & -1.490 & -17.22 & $<.0001$ \\
\hline C50 Breast cancer & -0.604 & 0.061 & -0.723 & -0.485 & -9.96 & $<.0001$ \\
\hline C53 Cervix uteri cancer & -0.998 & 0.098 & -1.190 & -0.805 & -10.16 & $<.0001$ \\
\hline C56 Ovary cancer & -0.590 & 0.066 & -0.720 & -0.460 & -8.90 & $<.0001$ \\
\hline C61 Prostate cancer & -1.499 & 0.088 & -1.672 & -1.326 & -16.98 & $<<.0001$ \\
\hline
\end{tabular}


Appendix Table 4

Complete estimates of In(DALYS_2015) model

\begin{tabular}{|c|c|c|c|c|c|c|}
\hline \multirow{2}{*}{\begin{tabular}{|l|}
\multicolumn{1}{|c|}{ Parameter } \\
$\begin{array}{l}\text { C64-C66 Kidney, renal pelvis and ureter } \\
\text { cancer }\end{array}$
\end{tabular}} & \multirow{2}{*}{$\begin{array}{c}\text { Estimate } \\
-1.087\end{array}$} & \multirow{2}{*}{$\begin{array}{c}\begin{array}{c}\text { Standard } \\
\text { Error }\end{array} \\
0.092\end{array}$} & \multicolumn{2}{|c|}{ 95\% Confidence Limits } & \multirow{2}{*}{$\begin{array}{c}\mathbf{Z} \\
-11.78\end{array}$} & \multirow{2}{*}{$\begin{array}{l}\operatorname{Pr}>|\mathrm{Z}| \\
<.0001\end{array}$} \\
\hline & & & -1.268 & -0.906 & & \\
\hline C67 Bladder cancer & -1.485 & 0.108 & -1.697 & -1.273 & -13.75 & $<.0001$ \\
\hline C70-C72 Brain and nervous system cancers & -0.407 & 0.100 & -0.603 & -0.210 & -4.06 & $<.0001$ \\
\hline C73 Thyroid cancer & -2.158 & 0.097 & -2.349 & -1.968 & -22.23 & $<.0001$ \\
\hline C81 Hodgkin lymphoma & -1.385 & 0.093 & -1.568 & -1.202 & -14.85 & $<.0001$ \\
\hline C82-C86, C96 Non-Hodgkin lymphoma & -0.691 & 0.037 & -0.764 & -0.619 & -18.69 & $<.0001$ \\
\hline C88, C90 Multiple myeloma & -0.762 & 0.080 & -0.918 & -0.607 & -9.59 & $<.0001$ \\
\hline C91-C95 Leukaemia & 0.000 & 0.000 & 0.000 & 0.000 & 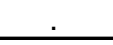 & \\
\hline Intercept & 5.021 & 0.267 & 4.498 & 5.543 & 18.83 & $<.0001$ \\
\hline
\end{tabular}

\begin{tabular}{|c|c|}
\hline \multicolumn{2}{|c|}{ GEE Model Information } \\
\hline Correlation Structure & $\begin{array}{c}\text { Independ } \\
\text { ent }\end{array}$ \\
\hline Subject Effect & $\begin{array}{c}\text { cause (19 } \\
\text { levels) }\end{array}$ \\
\hline Number of Clusters & 19.000 \\
\hline Correlation Matrix Dimension & 36.000 \\
\hline Maximum Cluster Size & 36.000 \\
\hline Minimum Cluster Size & 33.000 \\
\hline
\end{tabular}

\begin{tabular}{|l|c|}
\hline \multicolumn{2}{|c|}{ GEE Fit Criteria } \\
\hline QIC & 749.493 \\
\hline QICU & 737.000 \\
\hline
\end{tabular}

$\mathrm{N}=684$ (=19 cancer sites ${ }^{\star} 36$ countries). Disturbances are clustered within cancer sites. 


\section{Appendix Table 5}

Estimates of two-way fixed effects model of life-years lost (eq. (1)) based on sample excluding the USA

\begin{tabular}{|c|c|c|c|c|c|c|}
\hline Row & Parameter & Regressor & Estimate & Std. Err. & $\mathbf{Z}$ & $\operatorname{Pr}>|\mathrm{Z}|$ \\
\hline & \multicolumn{6}{|c|}{ Dependent variable $=$ DALYS 2015} \\
\hline 1 & $\beta_{0-4}$ & LAUNCHES_2011_2015 & -0.008 & 0.018 & -0.44 & 0.6608 \\
\hline 2 & $\beta_{5-9}$ & LAUNCHES_2006_2010 & -0.047 & 0.016 & -3.02 & 0.0025 \\
\hline 3 & $\beta_{10-14}$ & LAUNCHES_2001_2005 & -0.027 & 0.012 & -2.16 & 0.0309 \\
\hline 4 & $\beta_{15-33}$ & LAUNCHES_1982_2000 & -0.028 & 0.011 & -2.59 & 0.0095 \\
\hline \multirow[t]{2}{*}{5} & 4 & $\ln \left(C A S E S \_2012\right)$ & 0.870 & 0.033 & 26.36 & $<.0001$ \\
\hline & \multicolumn{6}{|c|}{ Dependent variable $=$ YLL_2015 } \\
\hline 6 & $\beta_{0-4}$ & LAUNCHES_2011_2015 & -0.006 & 0.019 & -0.32 & 0.7486 \\
\hline 7 & $\beta_{5-9}$ & LAUNCHES_2006_2010 & -0.050 & 0.016 & -3.17 & 0.0015 \\
\hline 8 & $\beta_{10-14}$ & LAUNCHES_2001_2005 & -0.027 & 0.013 & -2.15 & 0.0318 \\
\hline 9 & $\beta_{15-33}$ & LAUNCHES_1982_2000 & -0.030 & 0.012 & -2.55 & 0.0109 \\
\hline \multirow[t]{2}{*}{10} & $\gamma$ & $\ln ($ CASES_2012) & 0.869 & 0.037 & 23.38 & $<.0001$ \\
\hline & \multicolumn{6}{|c|}{ Dependent variable = YLD_2015 } \\
\hline 11 & $\beta_{0-4}$ & LAUNCHES_2011_2015 & -0.015 & 0.017 & -0.92 & 0.3593 \\
\hline 12 & $\beta_{5-9}$ & LAUNCHES_2006_2010 & -0.004 & 0.017 & -0.25 & 0.8006 \\
\hline 13 & $\beta_{10-14}$ & LAUNCHES_2001_2005 & -0.022 & 0.025 & -0.87 & 0.3843 \\
\hline 14 & $\beta_{15-33}$ & LAUNCHES_1982_2000 & -0.019 & 0.011 & -1.80 & 0.0713 \\
\hline \multirow[t]{2}{*}{15} & $\gamma$ & $\ln \left(\mathrm{CASES} \_2012\right)$ & 0.860 & 0.033 & 26.27 & $<.0001$ \\
\hline & \multicolumn{6}{|c|}{ Dependent variable $=$ YLL75_2015 } \\
\hline 16 & $\beta_{0-4}$ & LAUNCHES_2011_2015 & -0.012 & 0.028 & -0.42 & 0.6768 \\
\hline 17 & $\beta_{5-9}$ & LAUNCHES_2006_2010 & -0.077 & 0.026 & -2.97 & 0.003 \\
\hline 18 & $\beta_{10-14}$ & LAUNCHES_2001_2005 & -0.042 & 0.024 & -1.77 & 0.0761 \\
\hline 19 & $\beta_{15-33}$ & LAUNCHES_1982_2000 & -0.050 & 0.018 & -2.79 & 0.0053 \\
\hline \multirow[t]{2}{*}{20} & $\gamma$ & $\ln ($ CASES_2012) & 0.887 & 0.051 & 17.56 & $<.0001$ \\
\hline & \multicolumn{6}{|c|}{ Dependent variable $=$ YLL65 2015} \\
\hline 21 & $\beta_{0-4}$ & LAUNCHES_2011_2015 & -0.019 & 0.027 & -0.70 & 0.4838 \\
\hline 22 & $\beta_{5-9}$ & LAUNCHES_2006_2010 & -0.086 & 0.027 & -3.21 & 0.0013 \\
\hline 23 & $\beta_{10-14}$ & LAUNCHES_2001_2005 & -0.051 & 0.029 & -1.73 & 0.0836 \\
\hline 24 & $\beta_{15-33}$ & LAUNCHES_1982_2000 & -0.058 & 0.022 & -2.70 & 0.007 \\
\hline 25 & $\gamma$ & $\ln ($ CASES_2012) & 0.863 & 0.065 & 13.31 & $<.0001$ \\
\hline
\end{tabular}

Estimates in bold are statistically significant ( $p$-value $<.05)$.

$\mathrm{N}=684$ (=19 cancer sites ${ }^{\star} 36$ countries). Disturbances are clustered within cancer sites. 